\title{
Health System in China
}

\author{
David Hipgrave and Yan Mu
}

\section{Contents}

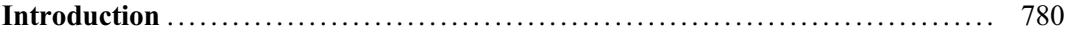

China's Current Health System Reform .............................. 781

Organization, Governance, and Accountability ........................ 783

Organization of the Health System .................................. 783

Accountability Within Government and to the Population ................... 784

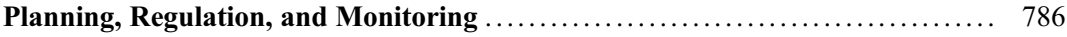

Monitoring Progress: China's Health Information Systems and Technology ........ 786

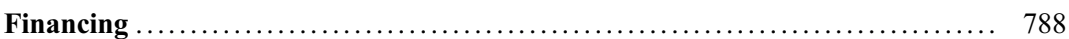

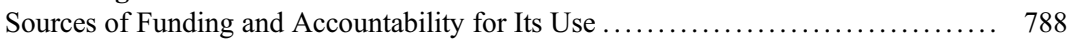

Difficulties Using Available Health Financing for Policy Implementation .......... 789

Health Expenditure and Sources of Revenue ............................. 790

Collection and Pooling of Funds ....................................... 790

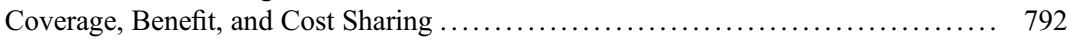

Payment Methods for Health Services .................................. 794

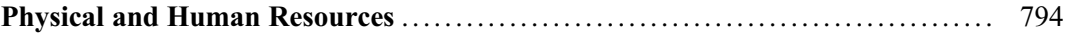

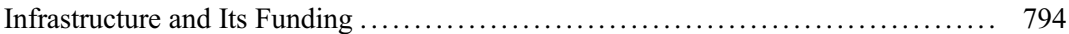

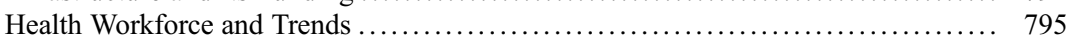

Remuneration of Health Workers ....................................... 797

Health Services Delivery and Outcomes ............................ 797

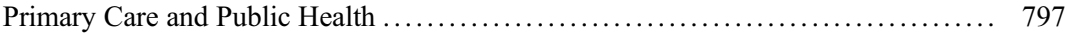

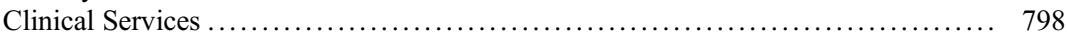

D. Hipgrave $(\bowtie)$

UNICEF, New York, NY, USA

Nossal Institute for Global Health, University of

Melbourne, Melbourne, VIC, Australia

e-mail: dhipgrave@gmail.com

$\mathrm{Y} . \mathrm{Mu}$

UNICEF China, Beijing, China

e-mail: ymu@unicef.org 


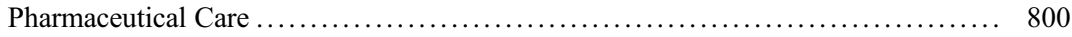

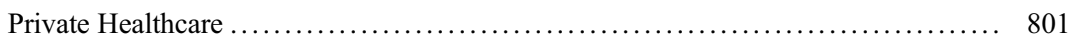

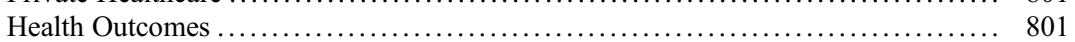

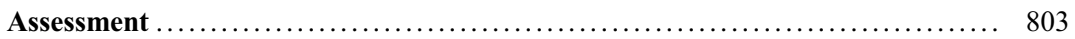

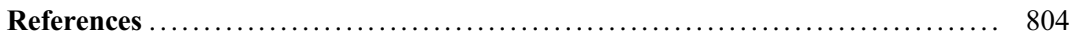

\section{Abstract}

The health of China's population improved dramatically during the first 30 years of the People's Republic, established in 1949. By the mid-1970s, China was already undergoing the epidemiologic transition, years ahead of other nations of similar economic status, and by 1980 , life expectancy (67 years) exceeded that of most similarly low-income nations by 7 years. Almost 30 years later, China's 2009 health reforms were a response to deep inequity in access to affordable, quality healthcare resulting from three decades of marketization, including de facto privatization of the health sector, along with decentralized accountability and, to a large degree, financing of public health services. The reforms are built on earlier, equity-enhancing initiatives, particularly the reintroduction of social health insurance since 2003 , and are planned to continue until 2020, with gradual achievement of overarching objectives on universal and equitable access to health services. The second phase of reform commenced in early 2012. China's health reforms remain encouragingly specific but not prescriptive on strategy; set in the decentralized governance structure, they avoid the issue of reliance on local government support for the national equity objective, leaving the detailed design of health service financing, human resource distribution and accountability, essential drug lists and application of clinical care pathways, etc. to local health authorities answerable to local government, not the Ministry of Health. Community engagement in government processes, including in provision of healthcare, remains limited. This chapter uses the documentation and literature on health reform in China to provide a comprehensive overview of the current situation of the health sector and its reform in the People's Republic.

\section{List of Abbreviations}

CDC Communicable disease control

GDP Gross domestic product

HMIS Health MIS

HSR Health system reform

LMIC Low- and middle-income countries

$\mathrm{MCH} \quad$ Maternal and child health

MDGs Millennium Development Goals

MIS Management information system

$\mathrm{MoH} \quad$ Ministry of Health

NCDs Noncommunicable diseases

NDRC National Development and Reform Commission

NEDL National Essential Drugs List

NEMS National Essential Medicines Scheme

NHFPC National Health and Family Planning Commission

PRC People's Republic of China

RCMS Rural cooperative medical (insurance) scheme

RMB Renminbi (unit of currency)

TCM Traditional Chinese medicine

THE Total health expenditure

UEBMI Urban employees basic medical insurance

URBMI Urban residents' basic medical insurance

\section{Introduction}

Most people are familiar with two things about modern China. The first is its physical size and enormous population. In land area, China is the world's third largest nation, theoretically spanning $4 \mathrm{~h}$ of time difference from west to east (while officially operating on one time zone). Its 2010 census revealed a population approaching 1.34 billion, the world's largest. China's population grew most rapidly from the late 1950 s to the 


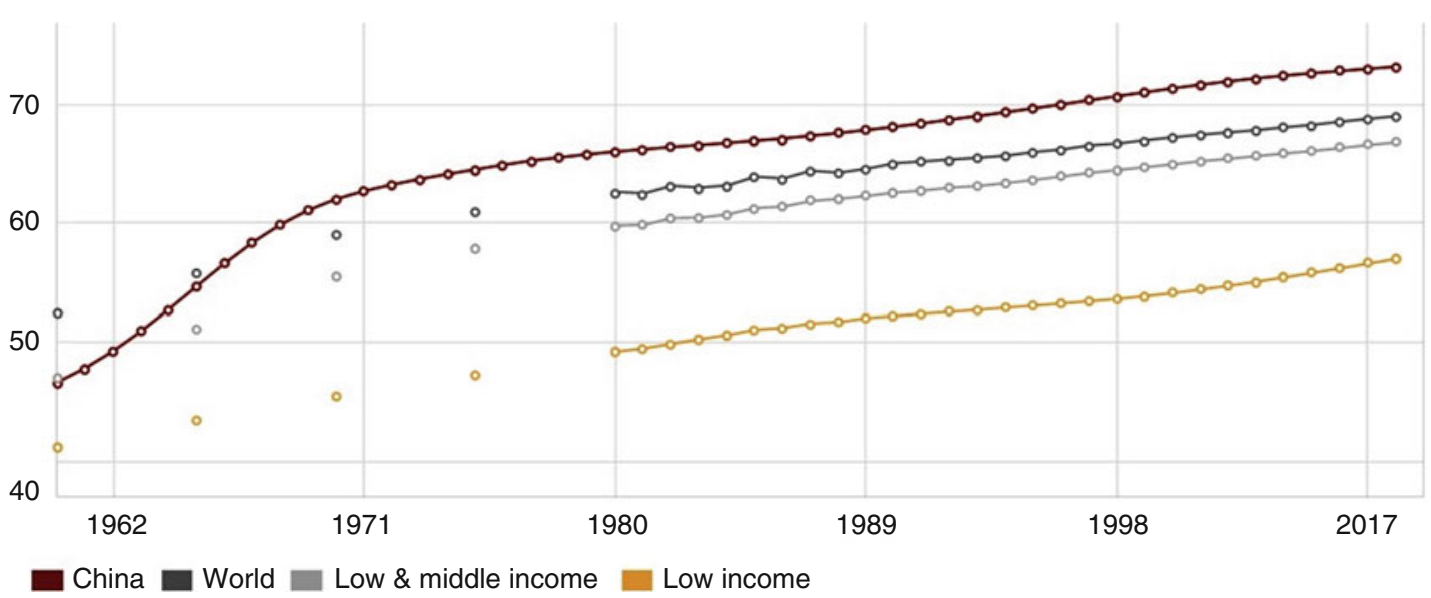

Fig. 1 Life expectancy in years: China, the world, and low-income and middle-income nations (Source: World Bank data available at http://data.worldbank.org/)

early 1970 s, due to the formerly high fecundity of its women alongside a rapid fall in the crude death rate due to communicable disease control (CDC) and basic public health measures. Life expectancy also rose rapidly during this period (Fig. 1) (Hipgrave 2011a).

The second familiar aspect is China's meteoric economic development, with an average annual growth rate of around $10 \%$ for most of the last 30 years, only falling to $7-8 \%$ since the global financial crisis.

These familiar aspects of China have depended on the health of its population improving dramatically during the first 30 years of the People's Republic of China (PRC) since its establishment in 1949. By the mid-1970s, China was already undergoing the epidemiologic transition, years ahead of other nations of similar economic status, and by 1980, life expectancy in low-income China (67 years) exceeded that of most similarly low-income nations by 7 years (Jamison et al. 1984).

However, with CDC (Hipgrave 2011a), economic development, rapid urbanization, and a dramatically ageing population, China's health system now faces a vastly different range of issues. China will soon become the first large nation to age before achieving developed nation status. Noncommunicable diseases (NCDs) now account for over $80 \%$ of deaths in China and almost $70 \%$ of its total disease burden (The World Bank Human Development Unit 2011). A World
Bank analysis of NCDs in China (The World Bank Human Development Unit 2011) concluded that "a reduced ratio of healthy workers to sicker, older dependents will certainly increase the odds of a future economic slowdown and pose a significant social challenge in China" (page 2). Equally challenging is the provision of new services for the prevention and management of chronic illness and the government's averred commitment to equity and universal health coverage. These challenges and commitments were among the stimuli to the major health system reform (HSR) that China commenced in 2009 (State Council 2009).

\section{China's Current Health System Reform}

China's most recent HSR was a response to deep inequity resulting from three decades of marketization and de facto privatization of the health sector. It was the culmination of many years of debate (Tang et al. 2014a) after acknowledged inaction on the heavy burden of healthcare on household expenditure (Blumenthal and Hsiao 2005; Huang 2011; Liu 2004; Liu et al. 2003; Tang et al. 2008). It comprises initiatives in five main areas:

1. Expanding the coverage and benefit of health insurance schemes in urban and rural areas

2. Establishing a national essential medicines scheme to ensure the availability of affordable 
medicines and reduce the ability of health providers to profit from the sale of drugs

3. Improving basic service availability and quality while also reducing referrals to specialist care and hospitals

4. Ensuring the availability of basic public health services for all populations

5. Piloting public hospital reform, particularly in order to separate hospital management and clinical service provision

The current HSR builds on earlier, equityenhancing initiatives including the reestablishment of rural health insurance (Meng et al. 2012) and subsidized hospital maternity services (Feng et al. 2010a). Early progress on the first phase of China's current HSR (2009-2012) was extensively reviewed, both internally by domestically commissioned teams of international (unpublished) and national experts (Wu and Yang 2013; Li and Chen 2012) and externally (Yip et al. 2012). The Reform is planned to continue to 2020, with gradual achievement of its overarching objectives on universal and equitable access to health services; the second phase (2012-2015) was announced in early 2012 (Ministry of Health 2012a), and a major additional pronouncement on county hospital reform was made in early 2014 (State Council 2014). Monitoring and evaluation of the Reform is slated to prioritize its different hierarchical elements (Figs. 2 and 3 ), although detailed plans for such evaluation have not been released.
China's commitment to HSR indicates its ongoing priority for the highest echelons of government (Ministry of Health 2012a). The four-year plan for phase 2 reiterates the goal of universal access to basic health services and seeks to resolve constraints to the supply of China's increasing and diverse health needs. It again commits to expanding insurance benefits and introduces priority to unifying China's several health insurance schemes; it encourages development of commercial insurance and the introduction of capitation and other payment reforms to separate doctors from the financial management of hospitals; it suggests that the private sector should manage $20 \%$ of health services by 2015 ; family general practice is promoted alongside expanding community and public health services, and the drug production, prescription, and pricing will be further consolidated and regulated; performancebased funding of health staff is also mentioned. These individual areas are discussed further below.

The plan is encouragingly specific but not prescriptive on strategy and avoids the issue of local accountability for financing various health programs, stipulating only that government spending on health should gradually increase as a proportion of total government expenditure. This vagueness hints at a major problem for China's health sector, the reliance on local government support for the national equity objective (Hipgrave et al. 2012). Another major problem remains the difficulty of reforming hospital management, effectively undoing the private, for-profit system that evolved over recent decades. As a result, China's
Fig. 2 Mapping China's health reform priorities over 2009-2020 (Source: WHO China)

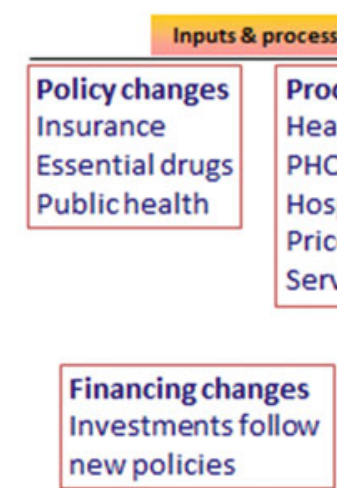

\section{Time $\rightarrow$}

2009 2010
Better quality

Efficiency in

service delivery
Impact

Results

Financial

protection

Patient

satisfaction

Health status 


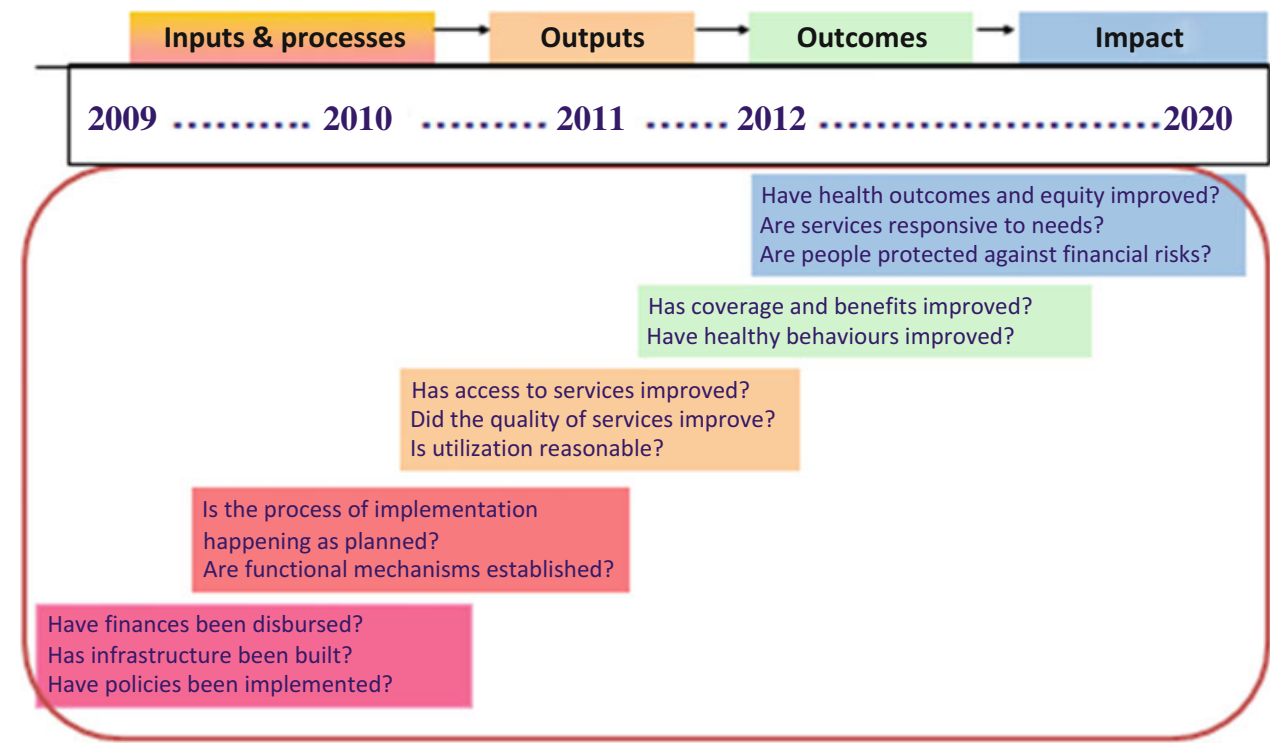

Fig. 3 Focus of monitoring and evaluation of health reforms in China (Source: WHO China)

HSR has not yet reduced the proportional financial burden of healthcare on households or their risk of catastrophic expenditure on health (Meng et al. 2012).

\section{Organization, Governance, and Accountability}

\section{Organization of the Health System}

China's former Ministry of Health $(\mathrm{MoH})$ recently merged with the body previously responsible for family planning to form the National Health and Family Planning Commission (NHFPC). The Commission contains 23 different departments, offices, and bureaux responsible for setting standards and for the planning, administration, oversight, and reporting on China's health sector. However, as with most of China's social sectors, there is a heavy decentralization of responsibility for local planning, financing, and implementation of health services in China (Wong 2010; Zhou 2010a). In China's decentralized system, policies and reform guidelines are set at national level but implementation is delegated to local authorities at provincial and lower levels. A hierarchy of health authorities oversees these issues at province, prefecture, county, and township levels.

In China's political economy and governance structure, local health authorities are more responsive to local government than to higher-level cadres within the health sector, meaning that uptake of national policies and recommendations is only guaranteed if there is broad agreement across all sectors of government and at local government level. In the past, when the health sector was of low priority, this severely limited the implementation of national laws relevant to the health sector. For example, the 1989 Law on Control of Infectious Diseases conferred on local government's responsibility for various forms of reporting and action, but was weakly implemented, culminating in the wake-up call of SARS in 2003, redrafting of the law and major reform of CDC (Hipgrave 2011a; Wang et al. 2008a). Initiatives depending on countrywide uptake such as the 2010 national measles vaccination campaign still rely heavily on local funding and prioritization; recent environmental degradation and food and drug safety scandals are further evidence of the lack of cross-sectoral priority given to the health sector in China. The partial 
rollback of the one-child policy announced at national level in 2013 remains subject to interpretation and optional implementation by provincial governments. Despite its evident high priority (Tang et al. 2014a), many aspects of the HSR itself are dependent on the same support and follow-up by provincial and even county governments (Hipgrave et al. 2012; Brixi et al. 2012).

To ensure that HSR would receive adequate local priority despite this structure and accountability, in early 2010 the HSR Leading Group in the State Council signed "accountability contracts" with provinces on key reform areas, for subsequent delegation and implementation at lower levels (China News Network 2010). In some provinces, a few key HSR targets such as health insurance coverage were incorporated into subnational officials' performance evaluation criteria, which has been effective in ensuring progress. However, in other, more complicated reform areas, such as strengthening primary healthcare, public hospital reforms, and others, ensuring progress has been more difficult. Indeed, the reform of public hospitals suffers from a lack of consensus or clear national guidance on direction, limiting its prioritization and implementation outside pilot areas, particularly at low levels.

\section{Accountability Within Government and to the Population}

Figure 4 illustrates the ideal accountability relationships among government, healthcare providers, and citizens (society) in the delivery of healthcare.
However in China, such relationships have not yet been forged. While there are promising moves to make local government generally more accountable to the public (such as measurement of "green gross domestic product (GDP)" and independent surveys of public opinion on local government performance in some provinces), the main motivation for subnational authorities remains economic development and revenue generation (Zhou 2010b). Moreover, while banking, communications, etc. are carefully regulated and monitored from above, like most social sectors, health services are largely organized and monitored at the local level. It is too costly for China's undermanned central government to independently monitor and evaluate subnational health performance (Wong 2010; Zhou 2010b). These circumstances explain the limited ability of national health officials to ensure the HSR is fully pursued at grassroots level.

In theory, all government plans represent the will of the people as they are ratified by the National People's Congress. However, many Congress members are unelected (in the western democratic sense) appointees, and the People's Congress generally rubber-stamps the documents presented. However, with the increasing attention of the Party and government in China to public comment through social media, albeit increasingly censored (Osnos 2014), and local protests, there is growing acknowledgment of their answerability to the general public. Therefore, while during local planning there is almost no formal process for the public to make input, there are opportunities for the general population to voice
Fig. 4 Accountability relationships for healthcare (Source: Adapted from The World Development Report 2004 (The World Bank 2003))

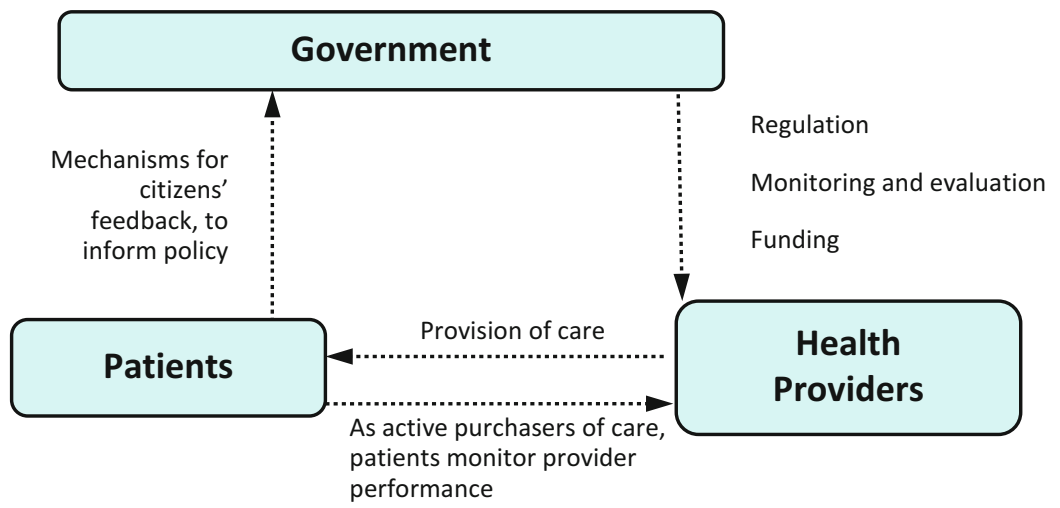


concerns through the courts, social media, petitions, protests, etc., especially when issues affect a significant proportion of a community. Although the process is usually slow (the HSR took many years to be formalized (Tang et al. 2014a)), there is usually gradual recognition and acknowledgment of the need to act. On the other hand, implementation of plans usually requires higher-level pressure on the various lower tiers of government, and this pressure progressively dissipates further down the hierarchy; it may be ignored for issues that don't have high-level and cross-sectoral support and the support of local government. Hence, targets for insurance coverage and drug price control are accepted, but controlling the environmental impact of local industry is often ignored (Human Rights Watch 2011). In this process, public influence is rather indirect and can be ignored if local economic, political, or vested interests override it.

Patients' concerns in healthcare delivery may be channeled formally through the National People's Congress at different levels (although usually only major complaints reach this level) or informally through social media. However, mechanisms to tap the feedback of patients, as the end users of health services, have not been established. There is no ombudsman or independent regulator in China's health system, and senior appointments are normally approved by the ruling Party organization. However, since launching the HSR, government is learning that empowering patients and regularly collecting their feedback on key parameters such as service prices and quality strengthens accountability across the government levels and can help achieve the overall goals of the reform (State Council 2014). Patient satisfaction and feedback is increasingly incorporated into the performance evaluation framework for HSR implementation (Ma 2013). However, this practice has not yet been standardized, systematized, and regularized throughout China.

An example of the problem China is having in effecting the most difficult aspect of the HSR, the reform of public hospitals, was recently summarized by eminent researchers on China (Yip et al. 2012), who noted the complex web of relationships that govern this endeavor (Fig. 5). It seems likely that China will need all the years up to 2020

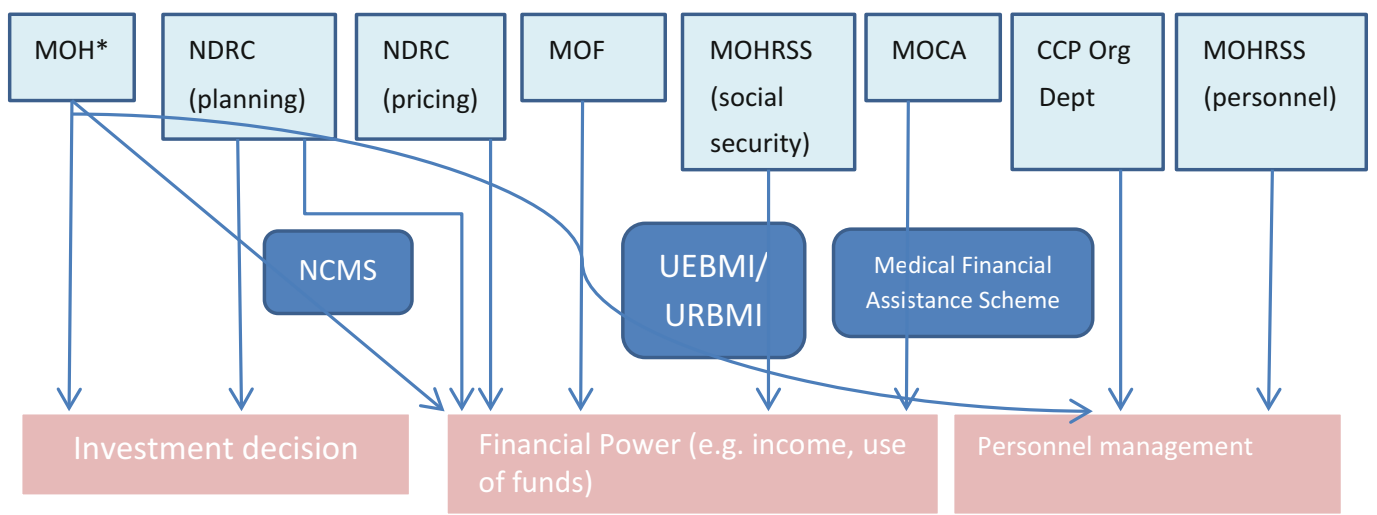

Public hospitals

Strategic planning and development
Use of profits and surplus
Staffing decisions
Management and use of assets
Fig. 5 Dispersion of power between ministries and public hospitals in China. *MOH Ministry of Health, NDRC National Development and Reform Commission, $M O F$ Ministry of Finance, MOHRSS Ministry of Human Resources and Social Security, MOCA Ministry of Civil
Affairs, CCP Org Dept Organizational Department of Chinese Communist Party, NCMS New Cooperative Medical Scheme, UEBMI Urban Employee Basic Medical Insurance, and URBMI Urban Residents Basic Medical Insurance (Based on Yip et al. 2012) 
to make progress in this area of reform, although some commentators doubt this will be achieved in the current context (Zhang and Navarro 2014).

\section{Planning, Regulation, and Monitoring}

The normal sector-planning practice in China follows the National Five-Year Plan for Social and Economic Development, with different social sectors (including health) developing their respective plans at five-yearly intervals with annual updates. However, the special need for health reform did not allow China's HSR to fall neatly in line with regular national development planning, which covers two five-yearly periods per calendar decade: the first three-year phase of the HSR covered 2009-2011, while the second overlaps with the latter part of the government's 12th Five-Year Plan period: 2012-2015. Moreover, the HSR was developed as a cross-sectoral endeavor led by the national planning ministry (the National Development and Reform Commission or NDRC) to address long-accumulated concerns of the population (State Council 2009; Tang et al. 2014a). While it overlapped with a $\mathrm{MoH}$ planning and development activity, Healthy China 2020, the HSR was not only a MoH initiative.

As part of the government's regular planning, the new NPFPC drafts annual national health work plans with annual targets and submits annual budget proposals for approval by the Ministry of Finance and the NDRC, which approves major construction initiatives such as health infrastructure development. With major events as the HSR, new changes and innovations are often seen in the plans year on year. At subnational levels, healthrelated authorities (not only health bureaux) in provinces, prefectures, and counties submit annual planning and budget proposals in line with health service delivery needs and stewardship to the development planning and finance authorities at the corresponding tier. Implementation is financed by local budget supplemented by transfers from higher tiers of government (explained below). Local data should be used in formulating plans, but as there is little tradition of regular, independent, or audited data gathering in
China, desensitization of administrative and economic data is suspected (Cai 2008; Hu et al. 2011; Walter and Howie 2011; Kaiman 2013; Anonymous 2012).

Regulation of the health sector follows the accountability structure outlined above and appraises progress and achievement against high-level targets set at national and local levels. Performance assessment tends to be quantitative (relating to coverage or throughput of health services), although assessment on more subtle measures such as patient satisfaction, service quality, and disease management has commenced (as outlined in a Guidance on Performance Assessment of Basic Public Health Services Delivery, jointly promulgated by Ministry of Health and Ministry of Finance in January 2011). At management level, government officials are also increasingly being appraised according to efficiency and innovations in rolling out reform initiatives at local level.

\section{Monitoring Progress: China's Health Information Systems and Technology}

With around $20 \%$ of the world's people, population-level changes in China's health status or indeed any globally important indicator have a major influence on corresponding global progress. For example, China's progress toward regional and global achievement of the Millennium Development Goal (MDG) targets will impact any final evaluation of the MDGs in 2015.

However, global statistics in any of the biological, physical, and social sciences can only be calculated if China's data is included and considered to be reasonably accurate, and data from China is not always available. Many lists of global indicators lack an entry from China, and the accuracy of what is released has been questioned (Cai 2008; Mulholland and Temple 2010). Usually, this is simply because China itself does not collect national statistics on the relevant indicators or not in ways comparable with other nations (e.g., see http://www.countdown2015mnch.org/documents/ 2012Report/2012/2012_China.pdf). However, as long ago as 2000, perspectives on China's 
mortality data were quite positive (Banister and Hill 2000).

The overall lack of data from China rouses suspicion. But while China's official statistics often lack breakdowns on key indicators (e.g., until recently, child mortality by gender or cause of death; nutrition status by province) or vary widely from one official source to the next (such as the annual birth cohort (Cai 2008) or number of road deaths (Hu et al. 2011)), these issues distract from China's efforts to improve the content, frequency, quality, and public availability of official data in recent decades (Banister and Hill 2000). Indeed, UNICEF's "Atlas on Children in China" publishes a wide range of official and recent data (http://www.unicefchina.org/ en $/$ index.php? $\mathrm{m}=$ content $\& \mathrm{c}=$ index $\& \mathrm{a}=$ lists $\&$ catid $=60$ ), and health statistics and other yearbooks are published annually (Ministry of Health 2012b; National Bureau of Statistics 2012, 2016) with a great degree of detail and disaggregation.

An increasing number of official and peerreviewed publications on maternal and child health $(\mathrm{MCH})$ in China report official government data (Wang et al. 2011, 2012; Rudan et al. 2010; Ministry of Health 2011a; Feng et al. 2010b, 2011), and this is contributing to summaries of global progress on the world's health status and MDGs 4 and 5. China relies on several different sources to provide health administrators, the public and academia with information on the health sector. While it has never conducted a demographic and health survey, and its last multi-indicator cluster survey was in 1995, China's national health services survey has been undertaken with a reasonably consistent methodology on a five-yearly basis since 1993. Many publications have used this source to assess progress in aspects of China's health system (Meng et al. 2012) and on its health indicators (Wang et al. 2012).

As an example of the other sources used, China's official MCH management information system (MIS) and the China Health Statistics Yearbook (Ministry of Health 2012b) rely on data from the following:

1. MCH Annual Reports: administrative reports submitted by $\sim 3000$ counties and districts across the nation (Ministry of Health 2007).
2. Maternal and Child Mortality Surveillance network, which has been summarized elsewhere (Wang et al. 2011).

3. The China Food and Nutrition Surveillance System, which surveys 40 surveillance sites on a five-yearly basis, most recently in 2010 .

4. The ten-yearly National Nutrition Survey, a comprehensive, age-stratified, sex-stratified, and geographically stratified survey with a sample size of almost 200,000 (last completed in 2012).

5. The China Immunization Registration and Information System, a newly computerized administrative system that reports vaccination coverage to the NHFPC.

6. Data gathered on health facilities, human resources, equipment, and services provided to outpatients and inpatients at various subnational levels and collected by the $\mathrm{MoH}$ Center for Health Statistics and Information.

7. China's National Notifiable Disease Reporting System, through which each county reports on 35 notifiable diseases. After SARS, this reporting system was massively upgraded to become web-based with reporting in real time (Fig. 6).

8. Disease Surveillance Points on births, deaths, and on cases of 35 notifiable diseases at 145 selected points around the nation.

9. China's Vital Registration System, which covers around $8 \%$ of the nation's population but is biased toward urban and eastern locations.

10. National Health Services Survey, which focuses on health status, service uptake, and health financing (Meng et al. 2012); it was last conducted in 2013.

11. National Census, last conducted in 2010 (National Bureau of Statistics 2012), including substantive demographic information.

12. National one percent (inter-census) Household Survey, conducted between the ten-yearly national censuses, last conducted in 2005 .

Notwithstanding recent attempts to improve the health MIS (HMIS), monitoring China's 

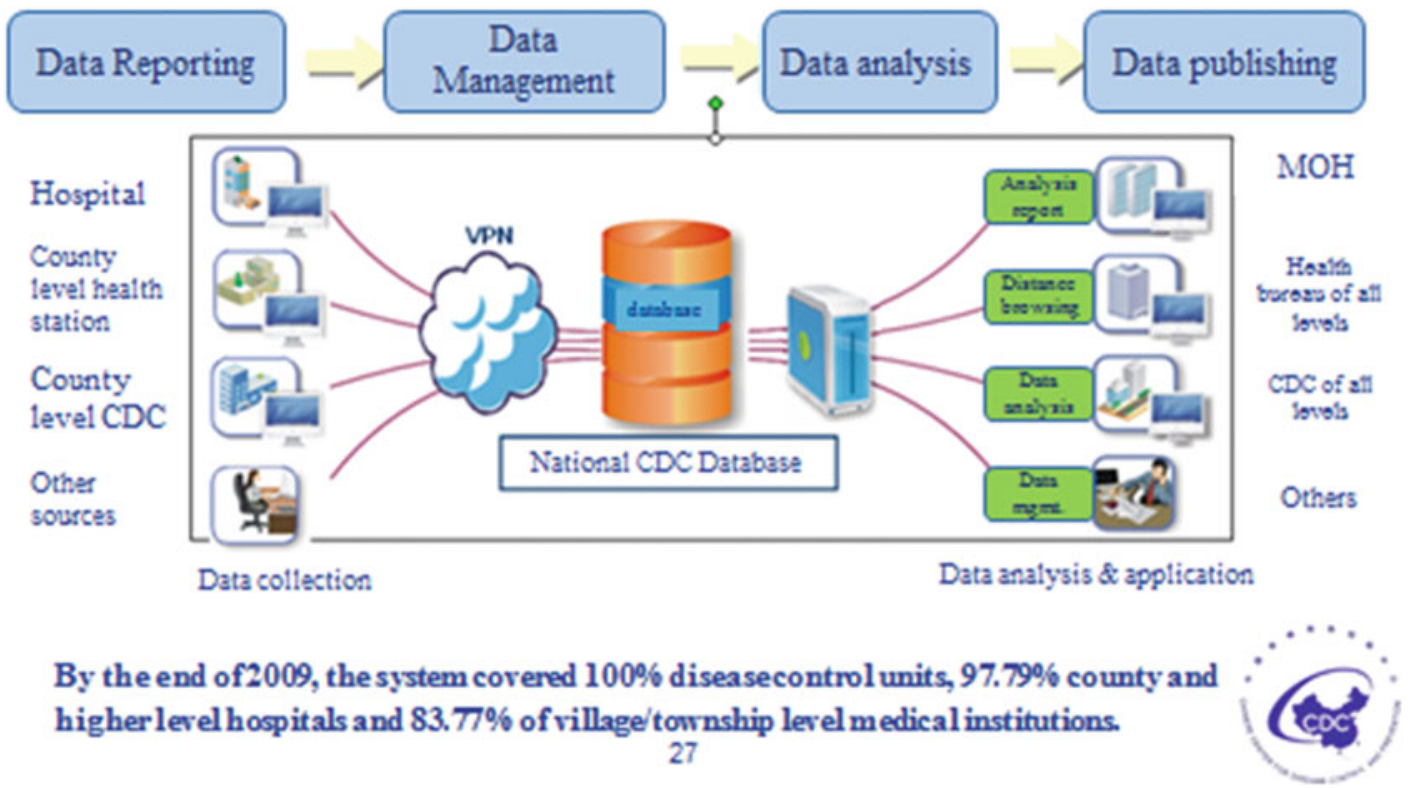

Fig. 6 Web-based national notifiable disease reporting since 2004 (Source: China Centre for Disease Control, Beijing (with permission))

HSR and health status relies largely on outputbased reporting or describes numeric improvements emanating from high-profile national initiatives (Meng et al. 2012), often lacking denominators (Huang 2011; Yip et al. 2012; Ministry of Health 2012c). China does not have a tradition of locally representative, populationbased surveys on health outcomes; those which are undertaken are almost never independent. The disaggregated impact of health initiatives and local health status remains unknown except at crude (regional and urban-rural) levels (Meng et al. 2012; Ministry of Health Centre for Health Statistics and Information 2009). This lack of data reduces the ability of governments to allocate resources according to local demography and disease epidemiology (which are changing rapidly with urbanization). In this context, quality implementation of new HMIS initiatives (Hipgrave 2011b) will be critical; however, again these are national initiatives reliant on local funding. The HMIS is mentioned as a priority for the second phase of the HSR (Ministry of Health 2012a), but in general the monitoring and evaluation of China's health sector remains weak and non-independent and is not prioritized at subnational level.

\section{Financing}

\section{Sources of Funding and Accountability for Its Use}

Subnational governments, even at county and township level, are responsible for about $90 \%$ of social sector financing and for the provision of essential services including health (National Bureau of Statistics 2011). Government expenditure on health depends heavily on local fiscal capacity (Yip et al. 2012; Wong 2010; Feltenstein and Iwata 2005); this varies widely across China, even after adjusting for formula-based "equalization transfers" from central government (Wong 2010; Bloom 2011). On average, tax revenue sharing and intergovernmental transfers finance up to $50 \%$ of subnational government expenditure (World Bank 2012).

This system bestows considerable power on provincial governments but also significant financial stress at the lowest levels of government. Each level of government has considerable discretion in transferring resources to successively lower levels. Provincial governments are the main recipients of the central government equalization 


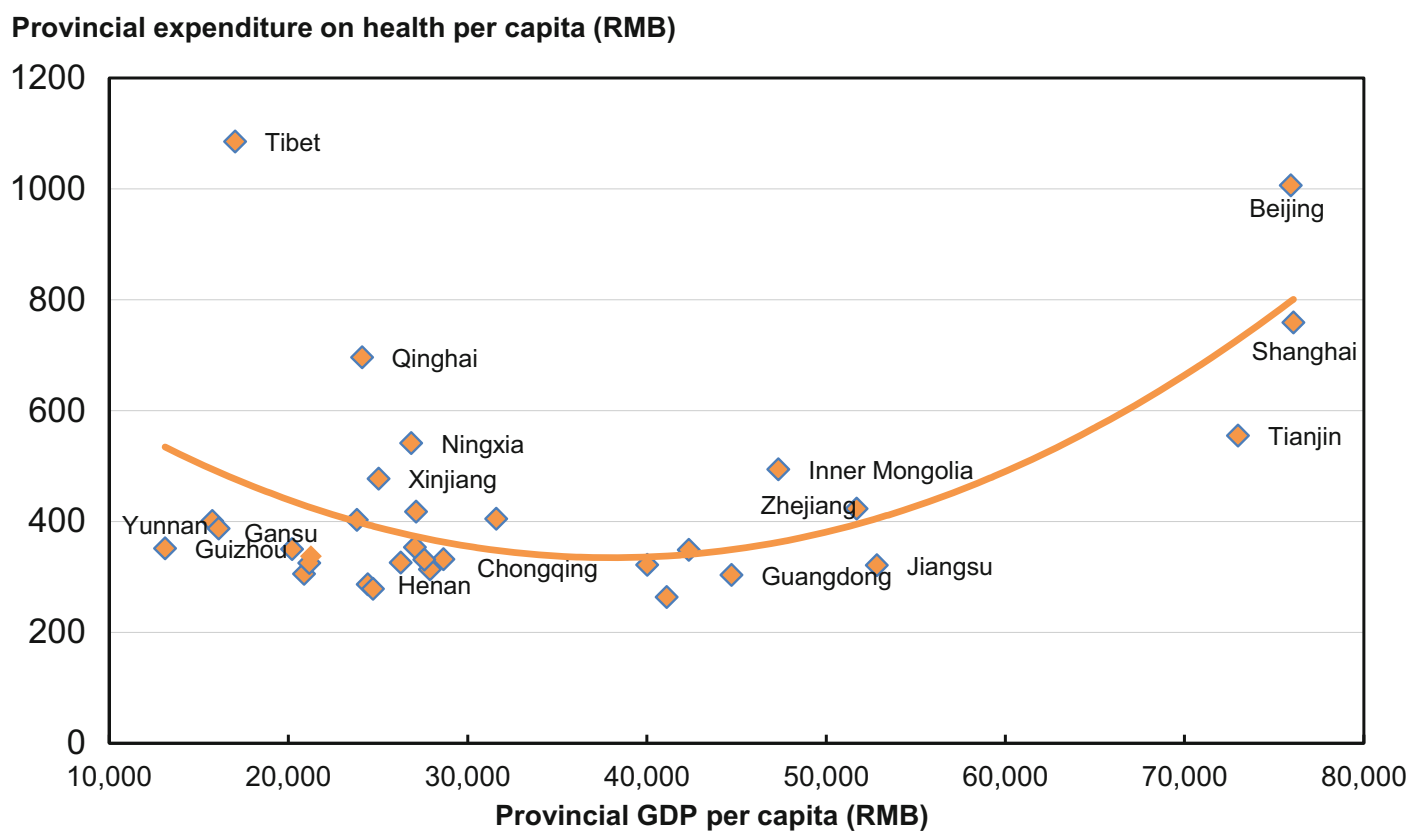

Fig. 7 Provincial expenditure on health per capita in relation to provincial gross domestic product per capita, 2010 (Source: Ministry of Health, China Health Statistics Yearbook, 2011 (Ministry of Health 2012b))

grants and tax sharing and have significant autonomy in what they do with these funds. Prefecture governments in turn have similar autonomy. In this system, funding for public service delivery by poorer townships and counties tends to be insufficient (Wong 2010; Zhou 2010b).

Apart from earmarked transfers from the $\mathrm{MoH}$ and funds for selected nationwide priorities, local governments may withhold resources for lower levels or favor spending in more populous areas or on issues strategic to their career (Zhou 2010a; Liu 2007). This kind of bias at subnational levels can undermine progress on national development goals (Yang 2011; Uchimura and Jütting 2007).

To supplement resources received from the higher levels, subnational governments raise resources from various fees, the sale of land use rights, and taxes on real estate transactions (World Bank 2012). However, poor localities tend to have limited scope for such revenue generation. The imbalance between resources and expenditure responsibilities, particularly in poor jurisdictions, impacts on health service quality (Yang 2011) and on household health expenditure
(Blumenthal and Hsiao 2005; Meng et al. 2012; World Bank 2012).

Moreover, income disparities have widened across localities and population groups within local jurisdictions (Xing et al. 2008; Zheng et al. 2008; UNDP China and China Institute for Reform and Development 2008). The national urban-rural ratio of income per capita has risen from 2.4 in 1991 to 3.2 (up to 4 within certain provinces) in 2010 (Fig. 7) (National Bureau of Statistics 2011). At subnational level, only four provinces (Sichuan, Tibet, Xinjiang, and Yunnan) bucked this trend due to large subsidies to stimulate economic development and poverty reduction. Subsidies for these provinces impact the shape of the line of best fit in Fig. 2, which depicts provincial expenditure on health in relation to provincial GDP, per capita.

\section{Difficulties Using Available Health Financing for Policy Implementation}

As mentioned, in China's decentralized environment, local government expenditures are not 
aligned with policy priorities across sectors and programs. There are four distinct components of the national budget system, two of which impact on social sector spending: the general government budget (which relies on various taxation revenues and allocates funds to publicly funded services and activities) and the social security budget. The first of these allocates funds at the sectoral level; line ministries can then decide on and allocate earmarked transfers to the provinces (Wong 2010; Zhou 2010b). However, subnational government spending also relies on off-budget revenues (such as local taxes) for off-budget programs.

Monitoring is limited and there is little effort to align subnational budgets or plans with higherlevel priorities. Moreover, apart from some individually monitored earmarked transfers, little information is available on whether governments actually spend money according to budgetary allocations or whether government expenditures and programs lead to the desired outputs and expected outcomes. Achievement of high-profile input and output HSR targets masks the absence of substantive analysis of outcome-level impact (Meng et al. 2012; Yip et al. 2012). Audits tend to focus on detecting malfeasance, not program performance.

Additionally, China's budget and expenditure cycles are not synchronous. The fiscal year starts with the calendar year, but the budget is not endorsed by the National People's Congress until the end of March. This delay reduces the budget's operational significance for subnational governments and central ministries (World Bank 2012). Fragmentation, information limitations, and delays in budget execution limit the ability of national authorities to transform policy priorities into resource allocation and results at the local levels (World Bank 2012).

\section{Health Expenditure and Sources of Revenue}

Total health expenditure (THE) in China was US\$445.5bn in 2012, at US\$329 per capita, and $5.41 \%$ of GDP (China National Health Development Research Centre 2013). THE/GDP is modest compared with industrialized countries, which averaged 9.7\% in 2010 (OECD 2013), but is average among low- and middle-income countries (LMIC), whose THE/GDP ranges from $2.6 \%$ to $10 \%$ (e.g., Indonesia 2.6\%, Thailand 3.9\%, India 4.1\%, Russia $5.1 \%$, Vietnam 6.8\%, South Africa 8.9\%, and Brazil, 9.0\%) (see data at http://apps.who.int/nha/data base). Health expenditure as a proportion of GDP has increased from $\sim 3 \%$ to $\sim 5 \%$ since 1980 , but numeric growth has been enormous due to China's rapid economic growth (Figs. 8, 9, and 10).

The sources of THE have changed dramatically over time, reflecting changes in the role of government. Marketization beginning in the 1980 s led to historically high out-of-pocket expenditure in 2001 (60\%), but this had decreased to $\sim 34 \%$ in 2012 (China National Health Development Research Centre 2013), mostly through public subsidies for primary health programs, for health providers and for the social insurance schemes.

In 2011, tax-based government expenditures accounted for $30.7 \%$ of THE, social health expenditure $34.6 \%$, and out of pocket $34.7 \%$ (Fig. 8). Overall, public expenditure on health as a share of THE is similar to that of many other LMIC and also to the United States (even higher if the government contribution to social health insurance is considered), but most high-income countries average around $71 \%$ (Tangcharoensathien et al. 2011). WHO calculates this figure differently and has China's figure at 56\%; most nations in South and East Asia average around $41 \%$ (see http:// apps.who.int/nha/database and Hipgrave and Hort 2014).

\section{Collection and Pooling of Funds}

To provide essential health services, reduce inequity, and provide financial protection against catastrophic health expenditure, governments must mobilize sufficient resources via: (1) collecting revenues, (2) pooling of risk, and (3) purchasing goods and services (Gottret and Schieber 2006). Globally, three models of basic healthcare financing are practiced: nationalized health services, social insurance, and private insurance. China's 


\section{Percentage of GDP}

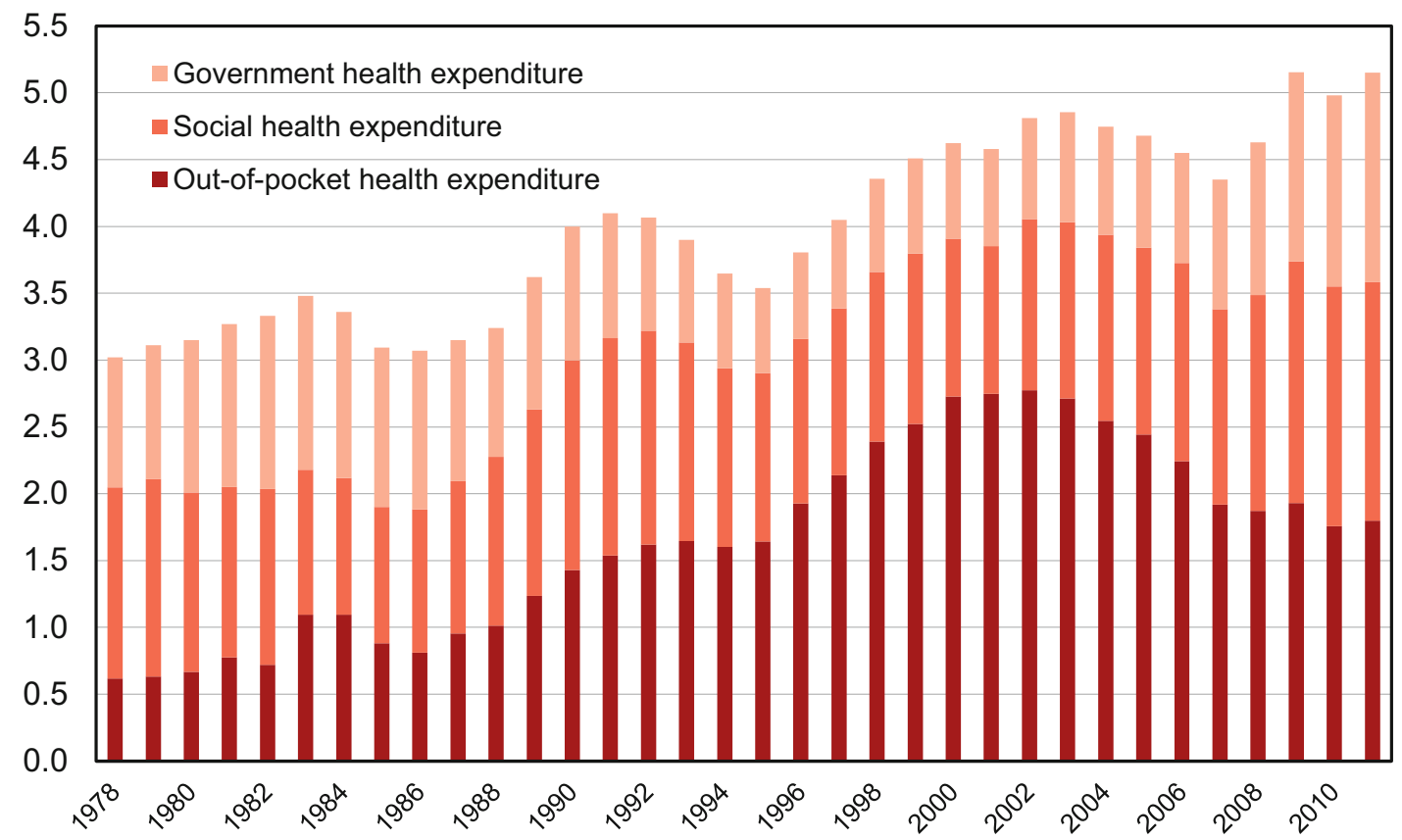

Fig. 8 Government, social and out-of-pocket expenditure on health, 1978-2011 (Source: China Health Statistics Yearbook (Ministry of Health 2012b))

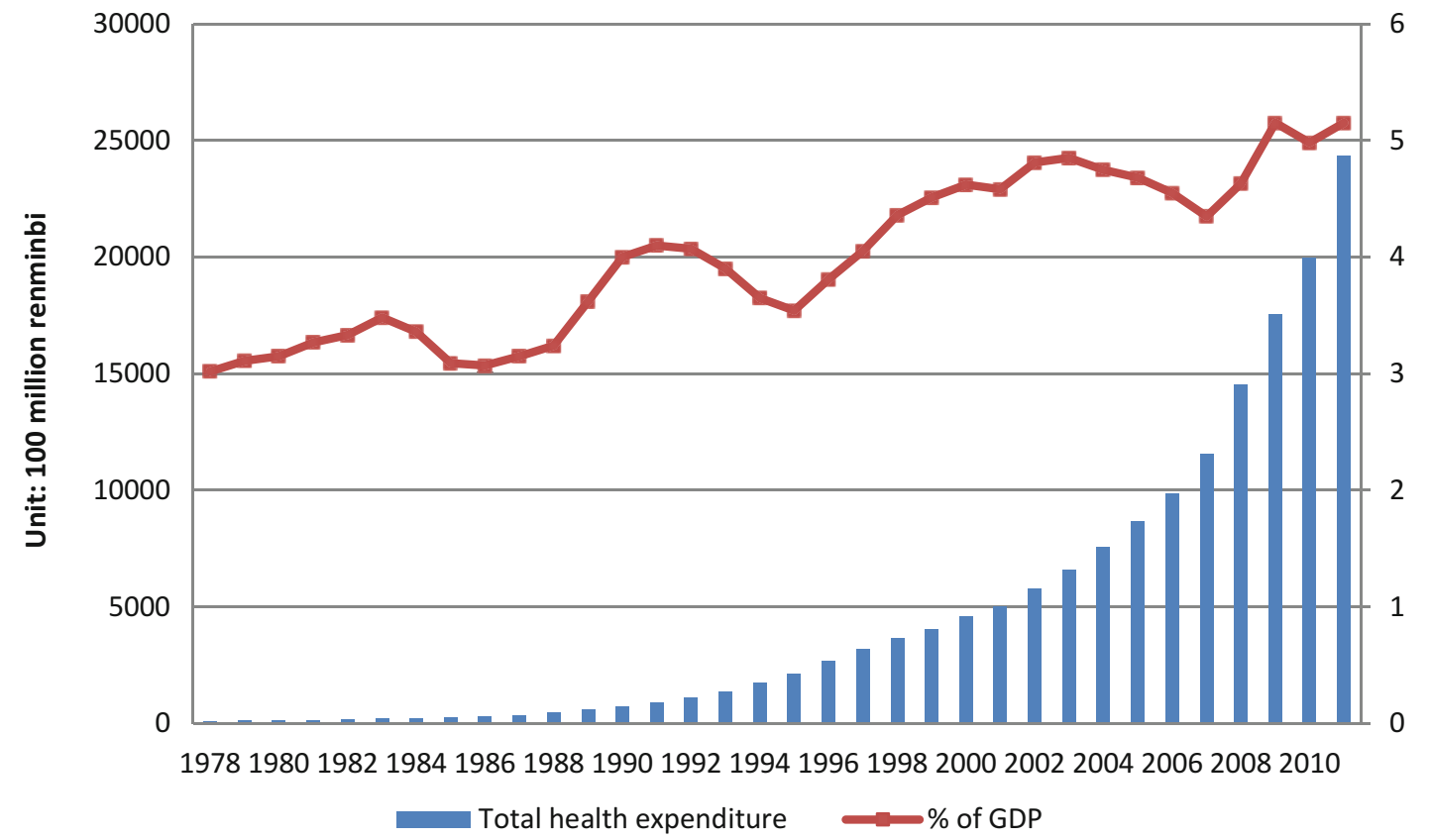

Fig. 9 Total health expenditure (THE) in China, numerically and as a percentage of gross domestic product (Source: China National Health Accounts Report 2012
(China National Health Development Research Centre 2012) (2012: US\$1 $=\sim 6$ renminbi $[\mathrm{RMB}])$ ) 


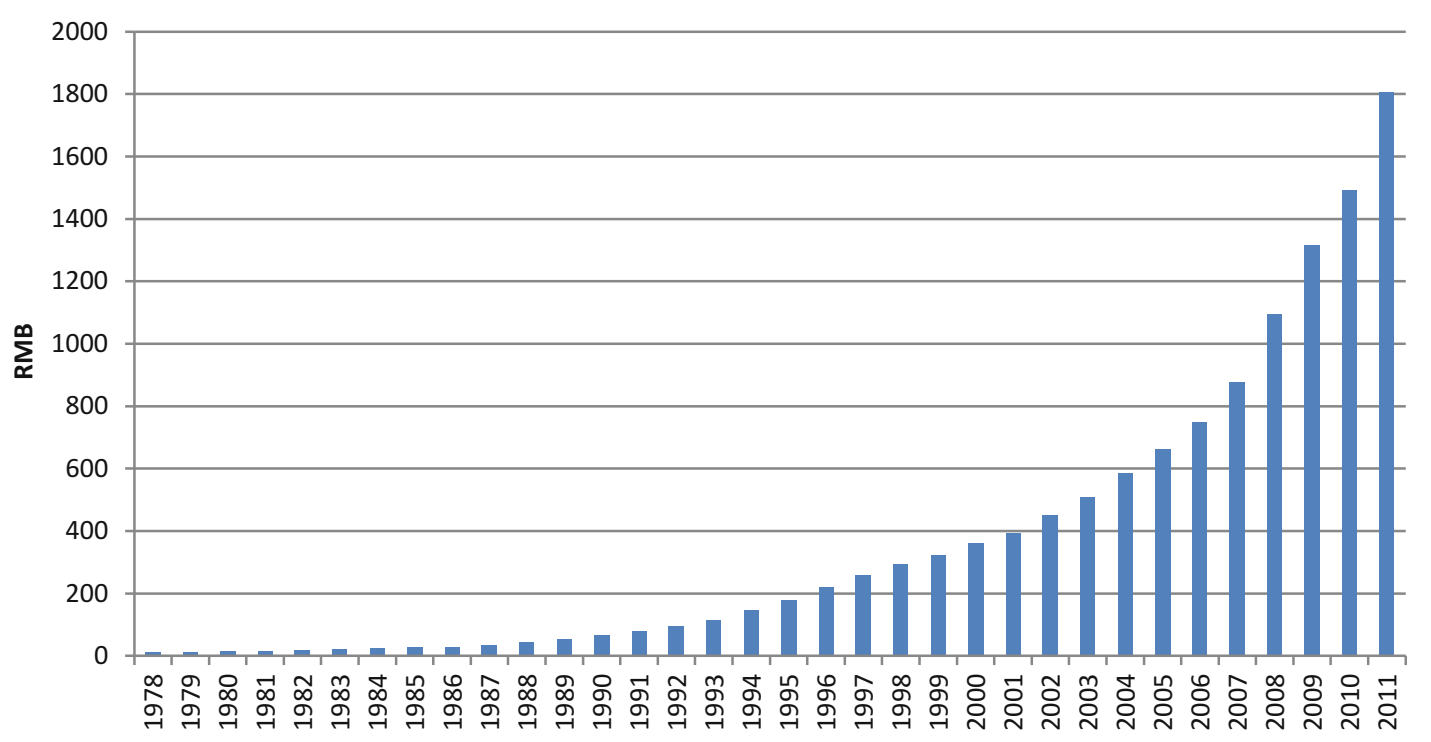

Fig. 10 China's per capita THE (Source: China National Health Account Report 2012 (China National Health Development Research Centre 2012))

healthcare financing has evolved to a structure dominated by three social insurance schemes with almost universal population coverage: the urban employees basic medical insurance (UEBMI) (financed by formal sector employers and employee contributions), the rural cooperative medical (insurance) scheme (RCMS), and urban residents' basic medical insurance (URBMI). The latter two receive heavy government subsidization in addition to individual contributions (in a roughly 4:1 ratio).

Government health expenditure stems from tax revenue, as described above. China does not have tax instruments specifically designated to health expenses; the funds are allocated from overall tax revenue. These funds are used to pay the salaries of health workers, purchase equipment, and build infrastructure at various levels and for various specific programs such as public health subsidies or other schemes earmarked by the MoH. Government also funds a social assistance program (the medical financial assistance scheme), which provides cash for designated poor households to purchase health services. There also remains "free medical treatment" for those on the government payroll and for retired military and Party cadres; these arrangements are slated for phasing out. However, government does not as yet contribute substantively to the funding of hospital care, which remains predominantly managed in-house from various sources of revenue (in particular, out-of-pocket payments and insurance) (State Council 2014; Barber et al. 2014).

\section{Coverage, Benefit, and Cost Sharing}

Table 1 summarizes the current basic health financing arrangements and benefit provided by the various health insurance schemes in China. It is evident that the major challenge remains fragmentation of the schemes and arrangements and the associated inequity and inefficiency. This is also highlighted in Fig. 11, which depicts the large variation in average numeric benefit and other information about the various schemes. In this context, and given China's highly mobile population and the limited access of migrant populations to urban health services (Di Martino 2011), the Government is prioritizing integration of the various insurance schemes (Ministry of Health 2012a), but this is a difficult and complex proposition. 







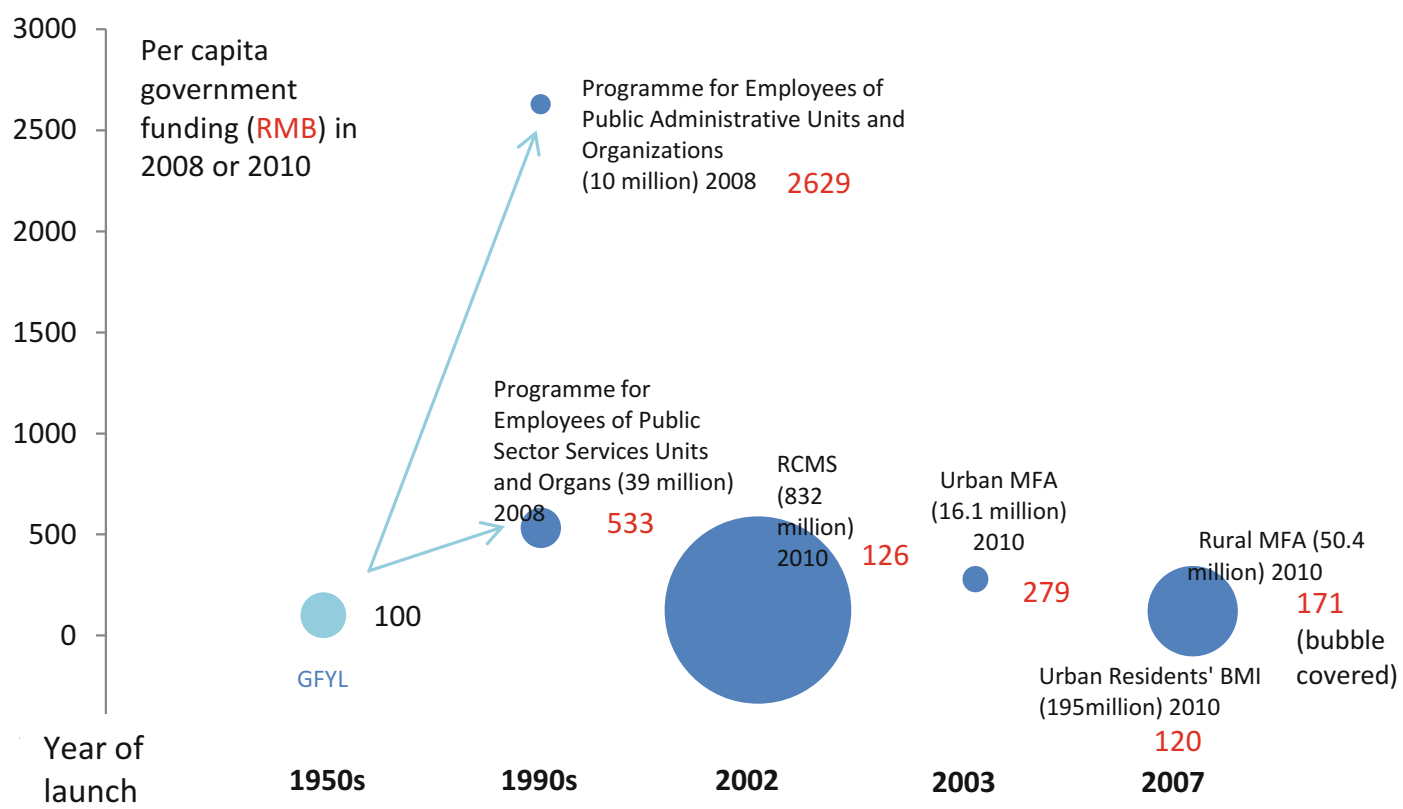

Fig. 11 Government financing per participant across health security schemes introduced during 1950-2007. Note: Bubble size is equivalent to the number of participants. Number of participants is shown in parentheses. Government spending per participant is shown in red.

\section{Payment Methods for Health Services}

Before the HSR, to ensure financial accessibility, the Chinese government priced primary healthcare services at below cost, but allowed providers to charge high prices for diagnostic tests using high-tech equipment, effectively cross-subsidizing primary services. Providers could also levy a $15 \%$ profit on drug sales. Under the prevailing fee-for-service payment modality, this created an incentive for providers to maximize profit by ordering tests and overprescription of drugs. Cost-effective and efficient primary healthcare services were ignored by providers because they were not profitable; those who could not pay for services often chose to forego them (Tang et al. 2008).

The recent reforms to provider payment, and those mooted for the future, aim to: (1) encourage the provision of cost-effective and efficient primary healthcare services, (2) reduce provider reliance on drug income and curb overprescription, and (3) curb cost inflation.
Government funding figures are annual per person, except for the rural and urban medical financial assistance, reported per case (Source: National Health Account Report 2011 and China Health Statistical Digest 2011)

Innovative provider payment methods, such as capitation (for primary heath mostly), gross budget, diagnosis-related groups (for hospitals), as well as performance-based payment for health workers, are being piloted at county and district level. Other related policy reforms include a zero markup policy (for essential drugs), implementation of essential drug list, and so on (Yang et al. 2013a).

\section{Physical and Human Resources}

\section{Infrastructure and Its Funding}

By international standards China's average health infrastructure level has been poor. For example, the number of hospital beds per 1000 population in 2011 was around 4, among the lowest in the world (Ministry of Health 2012b). Health infrastructure in China also suffered from a major urban-rural divide in the earlier stages of social and economic development. Not only did urban 
health infrastructure enjoy greater public financial support, it attracted loans and other financial instruments because it was profitable and boosted the local economy. For many years, rural facilities received very limited government subsidy and relied on collective funding among farmers. Rural health infrastructure lagged seriously, in terms of both the basic condition of health facilities (buildings, beds, etc.) and the equipment, while big urban hospitals acquired technical equipment of high quality. In 2005, there were 3.6 hospital beds per 1000 urban residents, but only 0.78 in rural townships (Ministry of Health 2007). This inequity was recognized by national government, and in 2006 the majority of a national bond issue was used to finance a project earmarked for rural health, specifically to finance the rebuilding, renovation, and updating of medical equipment for rural providers, including primary health facilities such as $\mathrm{CDC}$ and $\mathrm{MCH}$ institutions. The NDRC and its local branches approved the funding proposals for physical health infrastructure. More recently, the 2009 HSR allocated large sums to further improve physical health sector infrastructure (focusing on rural remote rural areas, but also urban community health centers). Progress on this aspect of the Reform has been very positive (Yip et al. 2012).

\section{Health Workforce and Trends}

For the majority of China's population, access to western and formally regulated traditional Chinese medicine (TCM) only commenced with the introduction of China's famed "barefoot doctors" in the mid-1960s. These cadres numbered 1.8 million at their peak (around one per 600 people), but numbers fell rapidly with economic marketization and liberalization of population movement (Bien 2008). Moreover, village-level care lost its funding base with the dismantling of the rural cooperatives in the early 1980s, and training and supervision of the quality of care provided fell off. As recently as the late 1990 s, many doctors lacked training to the level suggested by their rank and title (Youlong et al. 1997), and overprescribing of drugs and inappropriate use of parenteral preparations continue to exemplify the low quality of care, especially in rural areas (Blumenthal and Hsiao 2005; Bloom and Xingyuan 1997; Zhan et al. 1998; Pavin et al. 2003; Dong et al. 2008; Chen et al. 2010).

With economic marketization, medicine at all levels became privatized, physician salaries were paltry, standard consultation fees were fixed below cost (Eggleston et al. 2008), and over $40 \%$ of doctors' and health facilities' income derived from the sale of drugs ( $\mathrm{Hu} 2010)$. As a result, doctors worked where they could be assured of income, patients became disillusioned with the care at rural clinics, self-referral to urban clinics increased, and the distribution of doctors, nurses, and health facilities was heavily biased to urban areas (Yip et al. 2012; UNDP China and China Institute for Reform and Development 2008; Youlong et al. 1997; Anand et al. 2008) (Table 2). Residents of urban areas in China, particularly in the large eastern cities, enjoy physical access to health services to the same level as in most developed nations. However, like many other Asian nations, China has trained more doctors than nurses or midwives, and there are progressively fewer staff with formal health training in progressively poorer rural areas (Youlong et al. 1997; Anand et al. 2008) (Table 3). China includes TCM practitioners (13\%) in headcounts of health staff (Anand et al. 2008).

China is still paying for the interruption of university education during the Cultural Revolution of 1966-1976, and the paucity of new village doctors trained since the breakup of the village cooperatives in the late 1970s. First, as of 2005, $67.2 \%$ of China's doctors and $97.5 \%$ of nurses had only completed junior college or secondary technical school level training, and $6 \%$ and $8 \%$ respectively had just high school or lower education (Anand et al. 2008). The duration and standard of professional education varies widely across the country (Youlong et al. 1997). Village doctors are an ageing cohort, with a likely high attrition rate in the coming decade (Xu et al. 2014).

However, with massive increases in the number of formal trainees since 1998, the distribution and quality of personnel are probably bigger 
Table 2 Health workers in China in 2011

\begin{tabular}{|c|c|c|c|c|c|c|}
\hline \multirow[b]{2}{*}{ Categories } & \multicolumn{2}{|l|}{ Total } & \multicolumn{2}{|l|}{ Urban } & \multicolumn{2}{|l|}{ Rural } \\
\hline & $\begin{array}{l}\text { Number } \\
(1000 s)\end{array}$ & Density & $\begin{array}{l}\text { number } \\
(1000 \mathrm{~s})\end{array}$ & Density & $\begin{array}{l}\text { number } \\
(1000 \mathrm{~s})\end{array}$ & Density \\
\hline All health workers & 8616 & 4.58 & 3844 & 7.9 & 4762 & 3.19 \\
\hline $\begin{array}{l}\text { Licensed doctors including } \\
\text { assistant doctors }\end{array}$ & 2466 & 1.82 & 1190 & 3 & 1275 & 1.33 \\
\hline Nurses & 2244 & 1.66 & 1304 & 3.29 & 939 & 0.98 \\
\hline Other health professionals & 1492 & 1.1 & & & & \\
\hline Other health workers & 2413 & 1.8 & & & & \\
\hline
\end{tabular}

Note: Urban areas refer to jurisdiction under China's four municipalities and prefecture-level cities. Rural areas refer to counties and county-level cities, as well township hospitals and village clinics. Density refers to the number of health workers per 1000 population

Source: China Health Statistics Yearbook 2012 (Ministry of Health 2012b)

Table 3 Distribution of doctors and nurses by education level and health institution type, in 2011

\begin{tabular}{l|l|l|l|l|l|c}
\hline & \multicolumn{4}{|l|}{ In hospitals (\%) } & In community health centers (\%) & \multicolumn{3}{l}{ In township hospitals/clinics (\%) } \\
\cline { 2 - 7 } & Doctors & Nurses & Doctors & Nurses & Doctors & Nurses \\
\hline University and above & 62.7 & 11.5 & 31.7 & 5.7 & 3.9 & 0.4 \\
\hline $\begin{array}{l}\text { Secondary school and } \\
\text { college }\end{array}$ & 36.3 & 86.4 & 64.6 & 91 & 83 & 87.9 \\
\hline High school or less & 1 & 2.1 & 3.7 & 3.3 & 13.1 & 11.7
\end{tabular}

Note: University and above refer to with at least a bachelor's degree. Secondary schools include technical or professional high schools

Source: China Health Statistics Yearbook 2012 (Ministry of Health 2012b)

problems than the overall number of China's health human resources. Indeed, some data suggest an excess of trainees and the likelihood that many health graduates do not take up professional service. Nonetheless, inequality and inequity in the distribution of doctors and especially nurses between and particularly within provinces remains extreme and has been linked to key health outcomes including infant mortality (Anand et al. 2008).

Authorities in China recognize the prevailing inequity in distribution of health human resources and have initiated training and other schemes to increase the number of qualified personnel and improve their distribution. The 12th Five-Year Plan for health sector development, released in 2012, sets targets for assistant physicians (1.88/ 1000 population) and nurses (2.07) and lays out plans for increased priority of staffing in rural areas and at community level, of personnel and financial support for poor rural and western health facilities by wealthier urban and eastern facilities, of intensive efforts to fill known human resource gaps among various health and allied health providers, and of tiered registration for doctors that first requires a period of rural service. A focus on community general practice is reiterated in the plan, with a target of 150,000 staff newly trained or upgraded personnel to provide such services.

In addition, in a 2011 "Guidance" the State Council announced new roles for village doctors, recommending a wide range of tasks (Government of China 2011). By 2020, these cadres should be providing standardized primary care (following new clinical guidelines), implementing public health programs, undertaking disease surveillance, conducting community education, participating in health financing schemes, and maintaining individual e-health dossiers. In theory, it will be possible for the national HMIS to monitor their work. The official engagement of village doctors in a national system is positive development and should improve public confidence in their services. However, payment for 
the planned elevation of village doctors' responsibilities will derive from a complex mix of funding streams (Government of China 2011; Ministry of Health 2011b) overseen and additionally funded by county-level authorities (Government of China 2011) whose accountability for this national initiative will be to local government (Wong 2010; Zhou 2010b), not health authorities.

\section{Remuneration of Health Workers}

It is well established that marketization and the de facto privatization of clinical care by salaried doctors working in public facilities had, by 2000, resulted in China having one of the least equitable health systems in the world (The World Health Organization 2000), with over $60 \%$ of THE being out of pocket (Blumenthal and Hsiao 2005; Ho and Gostin 2009; Wang et al. 2007). One of the main objectives of China's HSR is to regulate the remuneration of doctors and to separate their income from choices on clinical care. However, while China has reduced the level of out-ofpocket expenditure on health to around 35\% through increases in public funding and insurance initiatives (Yip et al. 2012), household health expenditure has not decreased either numerically or as a proportion of total household expenditure (Meng et al. 2012). Although there is indirect evidence of increased non-health expenditure by insured households in comparison to before the schemes were introduced (Bai and $\mathrm{Wu} 2014$ ), this objective of the HSR is proving to be the most difficult to achieve. China's THE is increasing at around $17 \%$ per year, and a large proportion of the increase is due to payment of health facilities, doctors, and other providers by individuals or insurers. As patient expectations rise but out-ofpocket expenses remain numerically high, an increasing number of assaults of doctors by patients' families are being reported.

On the other hand, the scheduled fees payable to doctors for listed services are set below cost, forcing clinicians and facilities to charge for other services, investigations, procedures, and drugs (including those not on the essential drugs list with unregulated prices) (Blumenthal and Hsiao 2005; Ho and Gostin 2009; Wang et al. 2007; Tian et al. 2008) or through accepting bribes and kickbacks (Yang and Fan 2012). While the government has committed to improving both the quality of care provided by health providers, and is exploring remunerating them through capitation, diagnostic-related groups and performance-based incentives (Ministry of Health 2012a), separating hospital management from doctors' income is proving to be the most difficult element of the current HSR (Yip et al. 2012).

\section{Health Services Delivery and Outcomes}

\section{Primary Care and Public Health}

As reviewed elsewhere (Hipgrave 2011a), public health services in China suffered badly under the marketization of the 1980s and 1990s. CDC in particular was weak, culminating in the SARS epidemic in 2003. Public funding for preventive health services fell dramatically and was insufficient to even cover salaries. Public health authorities were left to raise their own income through charging fees for services, including vaccination (for which fees were only completely dropped in 2007) and various inspections and screening. Community approaches to disease control were abandoned in favor of vertical programs reliant on national or external funding, and disease surveillance was poor.

SARS and health authorities' realization of the epidemic of NCDs due to ageing, urbanization, and decreasingly active lifestyles has led to major changes to public health programming in China. Disease surveillance is now conducted online, in real time, and funding for $\mathrm{CDC}$ and preventive health has increased dramatically. New vaccines were introduced in 2008, although globally recommended vaccines against Haemophilus influenzae type $\mathrm{B}$, pneumococci, human papilloma viruses, and rotaviruses are only available privately (ironically, through government providers).

The largest boost to public health came with the 2009 HSR, when government introduced a 
minimum 15 renminbi (RMB)/capita subsidy for public health/screening activities to be conducted across the nation. This had been pre-dated by various vertical preventive health programs, such as funding of hepatitis B vaccine since 2002 (Cui et al. 2007) and national funding of the EPI since 2007. The HSR public health funding is provided by a mix of national and local authorities according to their ability to pay (problematic for poor counties in rich provinces) and the RMB15 was increased to RMB25 in 2011; it is much higher in wealthy areas. The funds pay providers to conduct the following services, notionally free of charge: (1) maintenance of individual electronic health records, (2) health education, (3) vaccination, (4) infectious diseases' prevention and treatment, (5) screening and management of chronic diseases such as hypertension and diabetes, (6) mental healthcare, (7) child healthcare, (8) pregnancy and maternity care, and (9) healthcare for the aged.

For the elderly and those with chronic diseases, this kind of screening, along with the introduction of zero markup and full reimbursement for drug treatment of NCDs (Yang et al. 2013a), has made a huge difference to their care. However, rollout of this initiative is slow, and although most targets are being met (Yip et al. 2012), monitoring is hampered by the absence of local denominators. Moreover, some of the programs, such as management of mental illness, have not been founded upon a training program for staff ill-equipped to provide them. In addition, unpublished evidence gathered by UNICEF in 2010 suggests that some of the funds are being used as salary supplements to support the new responsibilities of village doctors (in public health and other programs) and that the volume of money allocated to some rural localities is actually too high, due to out-migration to cities. Meanwhile, the increasing proportion of China's population living in urban areas, including most rural-urban migrants, cannot access such services.

Another boost to public health came with the MoH's program, also introduced in 2009, to prioritize interventions for certain vulnerable populations. These include: (1) catch-up hepatitis $B$ vaccination for those aged $<15$ years;
(2) cervical and breast cancer screening for women in rural areas; (3) an expansion of the hospital delivery subsidies first introduced in 2000 , to cover women in all rural counties; (4) free cataract surgery for the poor; (5) free folic acid supplementation for rural women before and during pregnancy; (6) improved stoves and fuel to reduce fluorosis; and (7) introduction of eco-friendly toilets. Again, targets for introduction of these measures have been set and rollout is proceeding (Yip et al. 2012).

Finally, although firm evidence of impact is scant, local authorities in most Chinese cities have introduced public education and health literacy programs to enhance awareness on issues like diet, exercise, cigarette smoking, appropriate care of women before and during pregnancy, infants and young children, and the elderly. As usual, implementation of national guidelines on such activities depends on uptake and funding by other sectors and local authorities. The regular occurrence of outbreaks of food (Xinhua 2011) and environmental contamination (Human Rights Watch 2011) and other scandals with public health implications indicates the difficulty faced by national authorities in China's decentralized context.

\section{Clinical Services}

Recent high-profile summaries of China's health system tend to focus on its administration and financing and neglect the considerable improvements in clinical care available to the local population. While standards at all levels of the service hierarchy vary very widely, health authorities have augmented the care available at virtually all public facilities across the nation. Moreover, access to services to services has improved for all the population, albeit at high cost to both government and individuals (Meng et al. 2012).

Clinical services in China are conducted through a hierarchically arranged network of facilities ranging from tertiary referral centers in the large cities (most having high-quality diagnostic and laboratory equipment) to second-tier hospitals at county and district level. Rural townships 
Table 4 Number of outpatient visits and inpatients in health institutions in China in 2011

\begin{tabular}{|c|c|c|}
\hline $\begin{array}{l}\text { Health institution } \\
\text { type }\end{array}$ & $\begin{array}{l}\text { Total visits } \\
(100 \text { million } \\
\text { person-times }) \\
(n=62.7)\end{array}$ & $\begin{array}{l}\text { Total inpatients } \\
(10,000 \text { persons }) \\
(n=15,298)\end{array}$ \\
\hline Hospitals $n(\%)$ & $22.6(36)$ & $10,755(70.3)$ \\
\hline $\begin{array}{l}\text { General-acute } \\
\text { hospitals }\end{array}$ & 16.74 & 8431 \\
\hline $\begin{array}{l}\text { Hospitals } \\
\text { specialized } \\
\text { in TCM }\end{array}$ & 3.61 & 1349 \\
\hline $\begin{array}{l}\text { Specialty } \\
\text { hospitals }\end{array}$ & 1.88 & 844 \\
\hline Sanitaria & 0.05 & 98 \\
\hline $\begin{array}{l}\text { Community health } \\
\text { institutions }(\%)\end{array}$ & $38.05(60.7)$ & 3775 (24.7) \\
\hline Health centers & 8.8 & 3472 \\
\hline $\begin{array}{l}\text { Urban health } \\
\text { centers }\end{array}$ & 0.11 & 23 \\
\hline $\begin{array}{l}\text { Rural township } \\
\text { hospitals }\end{array}$ & 8.7 & 3449 \\
\hline $\begin{array}{l}\text { Outpatient } \\
\text { department }\end{array}$ & 0.7 & 13 \\
\hline $\begin{array}{l}\text { Clinics, health } \\
\text { centers, and } \\
\text { nurse stations }\end{array}$ & 5.2 & \\
\hline $\begin{array}{l}\text { MCH centers } \\
\text { (stations) } n(\%)\end{array}$ & $1.76(2.8)$ & $682(4.28)$ \\
\hline $\begin{array}{l}\text { Specialized disease } \\
\text { prevention and } \\
\text { treatment institutes }\end{array}$ & 0.2 & 38 \\
\hline
\end{tabular}

Source: China Health Statistical Yearbook 2012 (Ministry of Health 2012b)

and urban communities are served by clinics or hospitals with varying capacity for inpatient care and surgery. At village or neighborhood level, public or (mostly) private facilities provide basic outpatient care, usually with an attached dispensary and possibly with links to a laboratory or radiology service. Concern about the standard of care provided by local facilities has resulted in many patients self-referring to higher-level facilities and hospitals (Table 4). As a result, hospitals in China tend to provide care for all level of illness, resulting in inefficiency and overcrowding. Expenditure on hospital-based care as a proportion of THE in China far exceeds that in many OECD nations (Barber et al. 2014), resulting in the high priority given to improving primary care, community general practice, and lower-level facilities in the HSR (Yip et al. 2012; Ministry of Health 2012a) and to moving outpatient care in particular from hospitals to primary care facilities (Barber et al. 2014).

As would be expected for a nation of this size and variation, clinical services in China vary widely, from the world-class care available to residents in Shanghai, Beijing, Guangzhou, and similar cities to the most basic care in rural clinics in far western China. Similarly, models for the care of chronic illness and the use of day-care and hospital in the home vary widely, but in general these options are not yet well developed in China. The average length of inpatient stay is high in China compared to OECD nations (Meng et al. 2012), particularly in public hospitals, which account for $89 \%$ of total beds and $92 \%$ of hospital admissions (Barber et al. 2014). Clinicians at community level have usually had training in TCM and many practice both western medicine and Chinese medicine.

However, the preparedness of clinicians in primary care for the wide range of conditions they treat varies widely. For example, China's current HSR acknowledges that the system's clinical focus has been ill-suited to the screening and outpatient care of chronic illness, an increasing priority as rates of noncommunicable diseases rise (The World Bank Human Development Unit 2011). Similarly, the high-volume model of clinical care in China is poorly suited to the management of mental illness (Qin et al. 2008), aged care and dementia, and prevention of tobacco-related illness and alcohol consumption, all of which are needed in China (The World Bank Human Development Unit 2011; Phillips et al. 2009; Yang et al. 2013b; Zhou et al. 2011; Chan et al. 2013).

With respect to quality of care, in the last decade China has moved to standardize many clinical pathways and practices, and the concept of evidence-based medicine is increasing. However, attention to such standards and their influence on clinical care is perceived to be low (Yang and Fan 2012). Moreover, funding for and the quality and independence of clinical research, access to information, and the ability of clinicians to practice independent of the profit motive are 
major obstacles to the use of evidence-based guidelines in clinical care in China (Barber et al. 2014; Wang 2010).

\section{Pharmaceutical Care}

China's pharmaceutical sector has been one of the most problematic for health authorities over recent decades and the focus of major reform efforts in the last few years. In 2008, 42.7\% of China's THE was on drugs (Hu 2010), compared to $17 \%$ in developed nations (Seiter et al. 2010). Excessive drug prescription was common in rural China (Zhan et al. 1998; Pavin et al. 2003; Dong et al. 2008; Chen et al. 2010; Yu et al. 2010), and there is evidence that China's rural health insurance scheme was encouraging overprescription (Chen et al. 2010; Sun et al. 2009). Drug sales continue to provide the largest income source for China's county health facilities; doctors have a pecuniary incentive to prescribe more and more expensive drugs (Chen et al. 2010; Yu et al. 2010). Hospitals and doctors profit significantly from the sale of drugs (Yu et al. 2010; The World Bank Group East Asia Pacific Region 2010), affecting financial access to healthcare (Tang et al. 2008; Meng et al. 2012). Weak regulation of drug manufacture and distribution raises safety concerns (Yu et al. 2010; Guan et al. 2011).

Previous efforts to improve the pharmaceutical sector had limited effect. The impact of laws, decrees, and 24 separate price reductions over 1996-2007 was constrained by hospital financing/income generation, market influences, and patient preferences (Chen et al. 2010; Yu et al. 2010). Price controls were undermined by manufacturers, wholesalers, and retailers and by hospitals and physicians controlling the prescription of price-controlled drugs (Hu 2010; Yu et al. 2010; Chen and Schweitzer 2008). New drug approvals were issued at astonishing rates (Ho and Gostin 2009) and the former head of the national drug administration authority was executed in 2007 for accepting bribes. Kickbacks and corruption continue to mar the sector (Yip et al. 2012; Yang and Fan 2012).
Acknowledging these problems, China's HSR included establishment of a National Essential Medicines Scheme (NEMS) to improve population access to and reduce the cost of essential medicines (State Council 2009), particularly at grassroots (township and village) level. The Scheme covers drug production, pricing, distribution, procurement, prescribing, and payment (Hu 2010) and a new National Essential Drugs List (NEDL) for primary healthcare institutions. The 2012 NEDL comprises 317 western drugs and 203 TCM commodities (increased from 205 western and 102 in 2009) for storage and use by grassroots facilities. Bidding prices for 296 NEDL drugs were capped (Schatz and Nowlin 2010), and a "zero markup" (no profit) policy was introduced, although markups remain allowed at county-level and higher facilities. By late January 2012, 99.8\% of township hospitals and $58.1 \%$ of village clinics had implemented the policy (Ministry of Health 2012d). In addition, most (urban) districts and (rural) counties had made NEDL medicines reimbursable by the various health insurance schemes, with higher reimbursement rates than for nonessential medicines (Ministry of Health 2011c). Finally, to regulate the pharmaceutical market and distribution of essential drugs, the NEMS introduced province-wise, collective, internet-based public bidding and procurement for NEDL medicines.

These four elements - the NEDL, zero markup, reimbursement of certain drug costs by insurers, and public procurement - were designed by the government to wrest control of the public pharmaceutical sector from the private sector. However, the official HSR documents encourage local adaptation of the broad design (Ho 2010), including the NEDL (which has indeed been widely augmented (Guan et al. 2011; Shi et al. 2011)) and strategies to compensate providers for the zero markup policy. Few evaluations of the impact of the Scheme have emerged. Very early indications suggested little change in prescribing practices (Yip et al. 2012), but a small field evaluation found that while drug procurement has been systematized and the cost of care had declined coincident with reduced drug prices, manufacturers have not 
uniformly supported the changes, and some drug prices have actually increased. Provider compensation for reduced income was mostly ineffective, forcing some to seek alternative sources of income within and outside the health sector. Rational drug prescribing had improved in this study. The loss of drug income had forced health facilities to rely more on public financing, and providers complained of higher workload and lower incomes (Yang et al. 2013a). Similar issues were found in another study in different locations (Xiao et al. 2013).

The NEMS particularly impacts small rural health facilities and will again rely on considerable local support for its implementation. Meanwhile, provinces are continuing to augment even a revised version of the NEDL (Tang et al. 2014a), and zero markup has not yet been applied in county or higher-level facilities. While insurance reimbursement and capitation may help to improve prescribing practices and reduce patient outlays, more control of procurement, manufacturer, and prescriber practices are required.

The recently announced reforms of county hospital funding and administration include a major focus on drug procurement, prescription, management, and pricing (State Council 2014).

\section{Private Healthcare}

As a consequence of the marketization of China's health sector in the 1990s, provision of health services was opened significantly to private providers. The number of private providers increased rapidly and now comprises a significant proportion of the market. For example, in 2005, private hospitals accounted for only $17.2 \%$ of total hospitals, but the share had increased to $38.4 \%$ by 2011. In 2011 among all 954,389 health facilities (hospitals, clinics, and other institutions), 47\% operated as "private" entities. Reports indicated that private health providers can offer services at a cheaper price and shorter physical distance and waiting time for patients (Deng et al. 2013) and are highly active in the provision of healthcare in China. However, most private facilities are small and poorly equipped, and collectively they only employed $17.5 \%$ of the total labor force, owned $9.7 \%$ of total medical beds, and received $9.1 \%$ of total patient hospital visits (Ministry of Health 2012b). Compared with public facilities, a large percentage of elderly physicians and new laborers in health market are practicing in private clinics (Tang et al. 2014b). This staffing structure could have negative impact on quality of services.

In general, despite rapid development in recent years, private health services are at an early stage of development in China. One major reason is that the evolution and current standing of national policy generally still favors public providers in terms of resource allocation, stewardship (entry and registration control), opportunities for promotion, and social insurance entitlements. This accounts for common challenges in the private sector, i.e., lack of technical capacity, poor infrastructure, and thus compromised service quality. Health authorities are now promoting a robust private sector to encourage competition and efficiency within the health sector, aiming for $20 \%$ of beds and services to be privately provided by 2015. However, subsidization of grassroots level public institutions may prevent moves in this direction.

\section{Health Outcomes}

While China's progress on major health indicators during the 30 years immediately following the foundation of the PRC is unparalleled (Jamison et al. 1984), marketization and the unaffordability of healthcare for a large proportion of the population stymied progress in the 1980s and 1990s. There are even suggestions that child mortality rates in China actually rose in the 1980s (Banister and Hill 2000), with the breakup of the communebased health cooperatives. Moreover, improvement in certain indicators has been slow. For example, urban maternal mortality has been slow to fall, almost certainly because reductions in maternity risk for urban residents have been diluted by the much higher risk of death in pregnancy among urban migrants (Fig. 12) (Zhang et al. 2014). Geographic disparities also remain great, particularly between eastern and western 


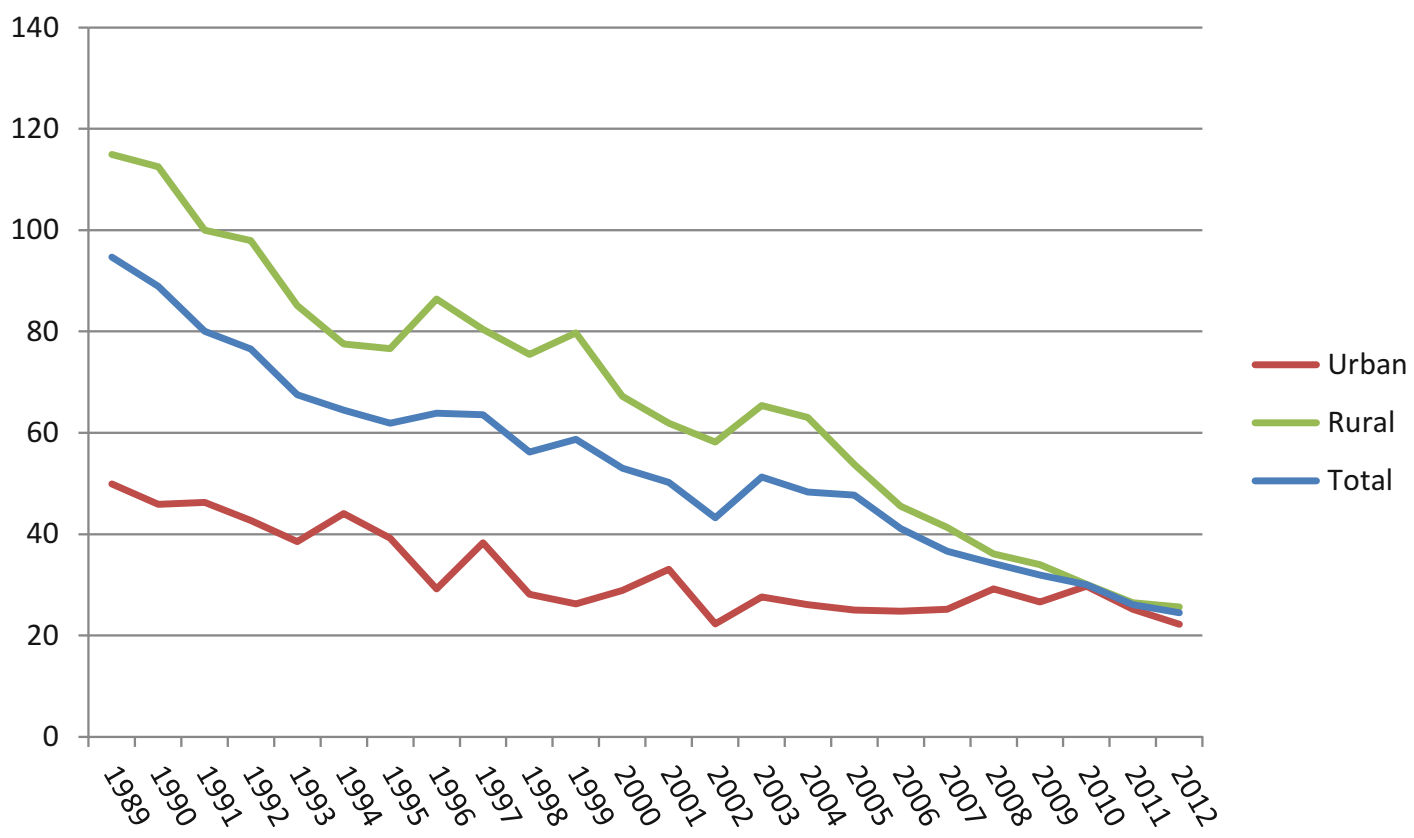

Fig. 12 Maternal mortality per 100,000 live births by urban-rural location (Source: China Health Statistics Year Book (Ministry of Health 2012b) and NHFPC (China National Health and Family Planning Commission 2012))

provinces (Wang et al. 2012). In general, the priority given to China's recent HSR acknowledges that progress in its population's health status was less than could have occurred, given the nation's economic growth since the 1980s (Yip et al. 2012). Acknowledgement of this is the government target of a one-year increase in life expectancy by 2015 (Ministry of Health 2012a). The most comprehensive analysis of the causes of death and disability in China, published in mid-2013, highlighted the dramatic evolution of its demographic transition, with NCDs now making up all but two of the top 30 causes of lost life years, and most infectious diseases having fallen precipitously. The report also noted the contribution of air and household pollution to mortality and morbidity and the need for cross-sectoral action to tackle the major causes of ill-health in China (Yang et al. 2013b).

Nonetheless, in 2010, average life expectancy in China was 74.8 years, and in 2012 the maternal mortality ratio was $24.5 / 100,000$ live births, infant mortality rate $10.3 \%$, and under-five mortality rate 13.2\%o (China National Health and Family Planning Commission 2012). These figures compare favorably with other developing countries, and China's performance in reducing rural maternal and neonatal mortality has been outstanding (Feng et al. 2010b, 2011). China has already achieved all the health targets in MDGs 4, 5, and 6 and achieved the target on reducing child underweight in the early 2000s. Urban-rural disparity in under-five and particularly maternal mortality has declined since 1990, but remains high for child underweight and stunting and especially for child micronutrient deficiency (UNICEF China, unpublished data; (Hipgrave et al. 2014)).

Challenges to population health status have been alluded to already and include the rise of NCDs, especially smoking-related illness (The World Bank Human Development Unit 2011), illness due to environmental damage and air pollution (The World Bank Human Development Unit 2011; Millman et al. 2008), urbanization, and the provision of services for newly arrived migrants (Gong et al. 2012). The prevention of accidents and injury will also play an increasing role in maintaining China's trajectory on reducing preventable death and ill-health (Wang et al. 2008b). As the population ages, 
private and institutional care of the elderly is another major issue for China's health and other social sectors.

\section{Assessment}

China's progress in maternal and child health, urban health, and communicable disease control are very encouraging, but the nation's health system now faces a vastly different range of issues from those it faced before.

In addition to health insurance reforms that commenced in 2003, in many ways the comprehensive health system reforms announced in 2009 have been highly successful. Insurance coverage is almost universal, and the benefit package is gradually expanding, even for outpatient services, although a system for ensuring coverage for the huge population of rural-urban migrants remains under development. Introduction of public health screening and management, building of new health infrastructure and expansion of community-based services, measures to control profiteering from the sales of drugs, scale-up training of health personnel, and other measures were both needed and are being implemented. On the other hand, the reform of hospital management and financing remains at the pilot stage, with suggestions but no formal guidance on the model to be followed.

China's HSR is encouragingly specific but not prescriptive on strategy. Monitoring the reform remains predominantly output-based at macrolevel; no detailed independent assessments have been undertaken, and population-level studies of health outcomes related to the reforms have not been undertaken. Moreover, mechanisms to incorporate patient feedback into health service provision have not been established and may be ignored if local economic, political, or vested interests override such input, as has been observed in relation to China's natural environment. Public financing of the health sector, although modest by global standards, has improved, particularly in relation to the proportion of THE that is out of pocket. But costs are rising faster than government inputs, and poorer constituencies remain least able to fund public services, despite having the greatest needs. As a result, proportional household expenditure on healthcare has not declined.

Urban residents of China's industrialized eastern provinces enjoy a high quality of healthcare and access to trained personnel. This is not the case for poorer rural residents, particularly in the nation's vast western region. The official engagement of village doctors to provide publicly funded health services in rural areas should improve the standard of and public confidence in their care, but the burden on this ageing cadre of staff is rising and may be untenable; again, accountability for this national initiative will be to local government and health officials unused to the application of treatment algorithms, performance-based assessment, and clinical audit. Concern about the care provided by community providers continues to result in many patients self-referring to higherlevel facilities and hospitals.

Population health in China is threatened by the rise of NCDs, especially illness due to diabetes, cardiovascular disease, overweight, tobacco smoking, environmental damage, and air pollution. The prevention of accidents and injury and management of mental illness will also play an increasing role in maintaining China's trajectory on reducing preventable death and ill-health. The required focus of the health sector on chronic illnesses, aged care, and outpatient services requires a dramatic increase in the engagement and stewardship of community providers.

This has been a major focus of China's health reforms, now well into their second phase, and it is likely that further major policy and financial inputs will be announced before this phase concludes in 2015. The private sector will play an increasing role in the provision of health services in China, but a higher level of stewardship and the use of financial mechanisms to reign in escalating costs will almost certainly be required, especially for hospital care. To ensure consistency and transferability, this may involve stronger oversight by and involvement of national health policy and financing authorities, notwithstanding the power vested in subnational authorities in China's system of government. 


\section{References}

Anand S, Fan VY, Zhang J, Zhang L, Ke Y, Dong Z, et al. China's human resources for health: quantity, quality, and distribution. Lancet. 2008;372:1774-81.

Anonymous. False data China's 'biggest source of corruption': statistics chief. Want China Times. 10 Apr 2012.

Bai $\mathrm{CE}, \mathrm{Wu} \mathrm{B}$. Health insurance and consumption: evidence from China's New Cooperative Medical Scheme. J Comp Econ. 2014;42:450-69.

Banister J, Hill K. Mortality in China 1964-2000. Popul Stud. 2000;58(1):55-75.

Barber SL, Borowitz M, Bekedam H, Ma J. The hospital of the future in China: China's reform of public hospitals and trends from industrialized countries. Health Policy Plan. 2014;29(3):367-78. https://doi.org/10.1093/heapol/ czt023.

Bien C. The barefoot doctors: China's rural health care revolution, 1968-1981. [Departmental Honors]: Wesleyan University; 2008.

Bloom G. Building institutions for an effective health system: lessons from China's experience with rural health reform. Soc Sci Med. 2011;72:1302-9.

Bloom G, Xingyuan G. Health sector reform: lessons from China. Soc Sci Med. 1997;45(3):351-60. Epub 1 Aug 1997.

Blumenthal D, Hsiao W. Privatization and its discontents the evolving Chinese health care system. N Engl J Med. 2005;353(11):1165-70. Epub 16 Sept 2005.

Brixi H, Mu Y, Targa B, Hipgrave D. Engaging sub-national governments in addressing health equities: challenges and opportunities in China's health system reform. Health Policy Plan. 2012. https://doi. org/10.1093/heapol/czs120.

Cai Y. An assessment of China's fertility level using the variable-r method. Demography. 2008;45(2):271-81. Epub 11 July 2008.

Chan KY, Wang W, Wu JJ, Liu L, Theodoratou E, Car J, et al. Epidemiology of Alzheimer's disease and other forms of dementia in China, 1990-2010: a systematic review and analysis. Lancet. 2013;381(9882):2016-23. Epub 12 June 2013.

Chen Y, Schweitzer SO. Issues in drug pricing, reimbursement, and access in China with reference to other AsiaPacific Region. Value Health. 2008;11(Suppl 1): S124-S9.

Chen W, Tang S, Sun J, Ross-Degnan D, Wagner AK. Availability and use of essential medicines in China: manufacturing, supply, and prescribing in Shandong and Gansu provinces. BMC Health Serv Res. 2010;10:211.

China National Health and Family Planning Commission. Statistical bulletin on national health and family planning development. National Health and Family Planning Commission of the PRC, Beijing; 2012.

China National Health Development Research Centre. China National Health Account 2011 (in Chinese). Beijing: China National Health Development Research Centre; 2012.
China National Health Development Research Centre. China National Health Account 2012 (in Chinese). Beijing: China National Health Development Research Centre; 2013.

China News Network. Ministry of Health signs "militarystyle order" on health reforms to improve poor accountability (in Chinese). China News Network [Internet]. 2010. Available at: http://www.chinanews.com/jk/jkylgg/news/2010/05-24/2299821.shtml. Last viewed 24 Oct 2014.

Cui FQ, Wang XJ, Cao L. Progress in hepatitis B prevention through universal infant immunization - China, 1997-2006. MMWR Morb Mortal Wkly Rep. 2007;56(18):441-5.

Deng G, Dou C, Gong Q. Ownership, fees and service quality by health providers. Econ Rev (Jingji Pinglun) (in Chinese). 2013;1:121-130.

Di Martino K. China: ensuring equal access to education and healthcare for children of internal migrants. In: Bhabha J, editor. Children without a state: a global human rights challenge. Cambridge, MA: MIT Press; 2011.

Dong L, Yan H, Wang D. Antibiotic prescribing patterns in village health clinics across 10 provinces of Western China. J Antimicrob Chemother. 2008;62(2): 410-5.

Eggleston K, Ling L, Qingyue M, Lindelow M, Wagstaff A. Health service delivery in China: a literature review. Health Econ. 2008;17(2):149-65.

Feltenstein A, Iwata S. Decentralization and macroeconomic performance in China: regional autonomy has its costs. J Dev Econ. 2005;76(2):481-501.

Feng XL, Shi G, Wang Y, Xu L, Luo H, Shen J, et al. An impact evaluation of the Safe Motherhood Program in China. Health Econ. 2010a;19(Suppl):69-94. Epub 14 Sept 2010.

Feng XL, Zhu J, Zhang L, Song L, Hipgrave D, Guo S, et al. Socio-economic disparities in maternal mortality in China between 1996 and 2006. BJOG. 2010b;117 (12):1527-36.

Feng X, Guo S, Hipgrave D, Zhu J, Zhang L, Song L, et al. China's facility-based birth strategy and neonatal mortality: a population-based epidemiological study. Lancet. 2011;378:1493-500.

Gong P, Liang S, Carlton EJ, Jiang Q, Wu J, Wang L, et al. Urbanisation and health in China. Lancet. 2012;379 (9818):843-52. Epub 6 Mar 2012.

Gottret PE, Schieber G. Health financing revisited: a practitioner's guide. Washington, DC: The World Bank; 2006.

Government of China. State Council Guidance on further strengthening the ranks of rural doctors (in Chinese). 2011. Available at: http://www.gov.cn/zwgk/2011-07/ 14/content_1906244.htm. Last viewed 24 Oct 2014.

Guan X, Liang H, Xue Y, Shi L. An analysis of China's national essential medicines policy. J Public Health Policy. 2011;32(3):305-19. Epub 27 May 2011.

Hipgrave D. Communicable disease control in China: from Mao to now. J Glob Health. 2011a;1(2):223-37. 
Hipgrave D. Perspectives on the progress of China's 2009 - 2012 health system reform. J Glob Health. 2011b;1(2):142-7. Epub 1 Dec 2012.

Hipgrave D, Hort K. Will current health reforms in south and east Asia improve equity? Med J Aust. 2014;200 (9):514.

Hipgrave D, Guo S, Mu Y, Guo Y, Yan F, Scherpbier RW, et al. Chinese-style decentralization and health system reform. PLoS Med. 2012;9(11):1-4.

Hipgrave DB, Fu X, Zhou H, Jin Y, Wang X, Chang S, et al. Poor complementary feeding practices and high anaemia prevalence among infants and young children in rural central and western China. Eur J Clin Nutr. 2014;68:916.

Ho CS. Health reform and de facto federalism in China. China Int J. 2010;8:33-62.

Ho CS, Gostin LO. The social face of economic growth: China's health system in transition. JAMA. 2009;301 (17):1809-11. Epub 7 May 2009.

$\mathrm{Hu} \mathrm{S}$. Financing, pricing and utilisation of pharmaceuticals in China: the road to reform. Beijing: The World Bank East Asia and Pacific Region; 2010. Contract No.: 58410

Hu G, Baker T, Baker SP. Comparing road traffic mortality rates from police-reported data and death registration data in China. Bull World Health Organ. 2011;89 (1):41-5. Epub 25 Feb 2011.

Huang YZ. The sick man of Asia. Foreign Aff. 2011;90:119-36.

Human Rights Watch. "My children have been poisoned": a public health crisis in four Chinese provinces. New York: Human Rights Watch; 2011.

Jamison DT, Evans JR, King T, Porter I, Prescott N, Prost A. China: the health sector. Washington, DC: The World Bank; 1984.

Kaiman J. Chinese statistics bureau accuses county of faking economic data. The Guardian. 7 Sept 2013.

Li L, Chen Q-L. A rational evaluation of China's health sector reform over three years. Health Econ Res. 2012;5:7-12.

Liu Y. China's public health-care system: facing the challenges. Bull World Health Organ. 2004;82(7):532-8. Epub 27 Oct 2004.

Liu MD. Sub-provincial intergovernmental fiscal transfers. 2006 Annual China Fiscal Reform Forum. Beijing: UNDP; 2007.

Liu Y, Rao K, Hsiao WC. Medical expenditure and rural impoverishment in China. J Health Popul Nutr. 2003;21(3):216-22. Epub 14 Jan 2004.

Ma XVC. National Commission for Health and Family Planning. Quoted comments given at press conference during 13th National People Congress 2013 (in Chinese). 2013. Available at: http://news.sina.com. $\mathrm{cn} / \mathrm{c} / 2013-03-15 / 035926536113 . s h t m l$. Last viewed 24 Oct 2014.

Meng Q, Xu L, Zhang Y, Qian J, Cai M, Xin Y, et al. Trends in access to health services and financial protection in China between 2003 and 2011: a cross-sectional study. Lancet. 2012;379(9818):805-14.
Millman A, Tang D, Perera FP. Air pollution threatens the health of children in China. Pediatrics. 2008;122 (3):620-8. Epub 3 Sept 2008.

Ministry of Health. The National Health Statistics reporting system (in Chinese). Beijing: Chinese Academy of Medical Science; 2007.

Ministry of Health. Report on women and children's health development in China. Beijing: China Ministry of Health; 2011a.

Ministry of Health. China's Minister of Health: rural doctors will continue to serve the masses indefinitely (in Chinese). 2011b. Available at: http://www.gov.cn/ gzdt/2011-02/18/content 1805889.htm. Last viewed 24 Oct 2014.

Ministry of Health. China 2010 health statistical yearbook. Beijing: China Ministry of Health; 2011c.

Ministry of Health. China's State Council announcement on deepening medical and health system planning and implementation of the program during the 12th Five Year Plan. 2012a. Available at: http://www.wpro.who. int/health_services/china_nationalhealthplan.pdf. Last viewed 24 Oct 2014.

Ministry of Health. China health statistics yearbook. Beijing: Chinese Academy of Medical Science; $2012 \mathrm{~b}$.

Ministry of Health. Three years of significant progress in health reform (in Chinese). 2012c. Formerly available at: http://www.moh.gov.cn/publicfiles/business/htmlfiles/ mohbgt/s3582/201201/53883.htm. Last viewed 20 Aug 2012 - MoH website now deleted.

Ministry of Health. Health statistical monthly reports. Beijing: Ministry of Health; 2012d.

Ministry of Health Centre for Health Statistics and Information. An analysis report of the fourth national health services survey in China in 2008. Beijing: China Union Medical University Press; 2009.

Mulholland K, Temple B. Causes of death in children younger than 5 years in China in 2008. Lancet. 2010;376(9735):89.

National Bureau of Statistics. China statistical yearbook (in Chinese). Beijing: National Bureau of Statistics; 2011. Available at: http://www.stats.gov.cn/tjsj/ndsj/ 2011/indexch.htm. Last viewed 24 Oct 2014.

National Bureau of Statistics. Tabulation of the 2010 population census of People's Republic of China. Beijing: China Statistics Press; 2012.

National Bureau of Statistics. China statistical yearbooks. Beijing: Published annually; 2016.

OECD. Health at a Glance: OECD Indicators, OECD Publishing. 2013. https://doi.org/10.1787/health_glance2013-en

Osnos E. China's censored world. New York Times. 2 May 2014.

Pavin M, Nurgozhin T, Hafner G, Yusufy F, Laing R. Prescribing practices of rural primary health care physicians in Uzbekistan. Trop Med Int Health. 2003;8(2):182-90.

Phillips MR, Zhang J, Shi Q, Song Z, Ding Z, Pang S, et al. Prevalence, treatment, and associated disability of mental disorders in four provinces in China during 
2001-05: an epidemiological survey. Lancet. 2009;373(9680):2041-53. Epub 16 June 2009.

Qin X, Wang W, Jin Q, Ai L, Li Y, Dong G, et al. Prevalence and rates of recognition of depressive disorders in internal medicine outpatient departments of 23 general hospitals in Shenyang, China. J Affect Disord. 2008;110(1-2):46-54. Epub 12 Feb 2008.

Rudan I, Chan KY, Zhang JS, Theodoratou E, Feng XL, Salomon JA, et al. Causes of deaths in children younger than 5 years in China in 2008. Lancet. 2010;375 (9720):1083-9. Epub 30 Mar 2010.

Schatz G, Nowlin P. Drugs for the masses. China Bus Rev. 2010;2010;22-5.

Seiter A, Wang H, Zhang S. A generic drug policy as a cornerstone to essential medicines in China. 2010. Contract No.: 58413.

Shi LW, Ma YQ, Xu LP, Zhao DH, Zhang Y. Review of adjustment of essential medicine list at provincial level in China. Value Health. 2011;14(3):A14.

State Council. Opinions of the Communist Party of China Central Committee and the State Council on deepening the health care system reform. 2009. Available at: http://www.china.org.cn/government/scio-press-confer ences/2009-04/09/content_17575378.htm. Last viewed 24 Oct 2014.

'State Council. Opinions on promoting the comprehensive reform of county public hospitals (in Chinese). 2014. Available at: http://baike.baidu.com/link?url= jPS0SkO7GzuPcuhNHwpFhXEFOaPjpJ8PKVX7_Gz RMhMUYnG_u-THEs_dlop84b77tO3Y2PXMSoXy KJ5gLPtyg. Last viewed 5 July 2014.

Sun X, Jackson S, Carmichael GA, Sleigh AC. Prescribing behaviour of village doctors under China's New Cooperative Medical Scheme. Soc Sci Med. 2009;68 (10):1775-9. Epub 4 Apr 2009.

Tang S, Meng Q, Chen L, Bekedam H, Evans T, Whitehead M. Tackling the challenges to health equity in China. Lancet. 2008;372(9648): 1493-501. Epub 22 Oct 2008.

Tang S, Brixi H, Bekedam H. Advancing universal coverage of healthcare in China: translating political will into policy and practice. Int $\mathrm{J}$ Health Plann Manage. 2014a;29(2):160-74. https://doi.org/10.1002/hpm.2207

Tang C, Zhang Y, Chen L, Lin Y. The growth of private hospitals and their health workforce in China: a comparison with public hospitals. Health Policy Plan. 2014b; 29(1):30-41. https://doi.org/10.1093/heapol/czs130

Tangcharoensathien V, Patcharanarumol W, Ir P, Aljunid SM, Mukti AG, Akkhavong K, et al. Health-financing reforms in southeast Asia: challenges in achieving universal coverage. Lancet. 2011;377(9768):863-73. Epub 29 Jan 2011.

The World Bank. World development report 2004: making services work for the poor people. Washington, DC: The World Bank; 2003.

The World Bank Group East Asia Pacific Region. Fixing the public hospital system in China. Washington, DC; 2010. Contract No.: 58411.

The World Bank Human Development Unit. Toward a healthy and harmonious life in China: stemming the rising tide of non-communicable diseases. Washington, DC: The World Bank; 2011.

The World Health Organization. The world health report 2000: health systems: improving performance. Geneva: World Health Organization; 2000.

Tian Y, Hua LJ, Chao WM. Chinese doctors' salaries. Lancet. 2008;371:1577.

Uchimura H, Jütting, J. Fiscal decentralization, Chinese style: good for health outcome? OECD Development Centre Working Paper \#264. Paris: OECD; 2007.

UNDP China, China Institute for Reform and Development. China national human development report 2007/ 2008: access for all: basic public services to benefit 1.3 billion people. Beijing: UNDP; 2008.

Walter CE, Howie F. Red capitalism: the fragile financial foundation of China's extraordinary rise. Singapore: Wiley; 2011.

Wang J. Evidence-based medicine in China. Lancet. 2010;375(9714):532-3. Epub 18 Feb 2010.

Wang H, Xu T, Xu J. Factors contributing to high costs and inequality in China's health care system. JAMA. 2007;298(16):1928-30. Epub 24 Oct 2007.

Wang L, Wang Y, Jin S, Wu Z, Chin DP, Koplan JP, et al. Emergence and control of infectious diseases in China. Lancet. 2008a;372(9649):1598-605. Epub 22 Oct 2008.

Wang SY, Li YH, Chi GB, Xiao SY, Ozanne-Smith J, Stevenson $\mathrm{M}$, et al. Injury-related fatalities in China: an under-recognised public-health problem. Lancet. 2008b;372(9651):1765-73. Epub 22 Oct 2008.

Wang YP, Miao L, Dai L, Zhou GX, He CH, Li XH, et al. Mortality rate for children under 5 years of age in China from 1996 to 2006. Public Health. 2011;125(5):301-7. Epub 29 Apr 2011.

Wang Y, Zhu J, He C, Li X, Miao L, Liang J. Geographical disparities of infant mortality in rural China. Arch Dis Child Fetal Neonatal Ed. 2012;97(4):F285-90. Epub 17 Jan 2012.

Wong C. Public Sector Reforms toward Building the Harmonious Society in China. Paper prepared for the China Economic Research and Advisory Programme. University of Oxford; 2010.

World Bank. China 2030: building a modern, harmonious, and creative high-income society. Washington, DC: The World Bank; 2012.

Wu N, Yang HW. Retrospective evaluation of the achievements of the implementation of essential medicine system in medical reform of past three years. China Pharm. 2013;10(5-6):78-82.

Xiao Y, Zhao K, Bishai DM, Peters DH. Essential drugs policy in three rural counties in China: what does a complexity lens add? Soc Sci Med. 2013;93:220-8. https://doi.org/10.1016/j.socscimed.2012.09.034.

Xing L, Fen S, Luo X, Zhang X. Intra rural income disparity in West China. China Econ Q. 2008;1(1):329-50.

Xinhua. China penalizes 113 over chemical tainted pork. China Daily. 26 Nov 2011 10:36.

Xu H, Zhang W, Gu L, Qu Z, Sa Z, Zhang X, et al. Aging village doctors in five counties in rural China: situation 
and implications. Hum Resour Health. 2014;12:36. Epub 30 June 2014.

Yang DL. The central-local relations dimension. In: Freeman $\mathrm{CW}, \mathrm{Lu} \mathrm{XQ}$, editors. Implementing health care reform policies in China. Washington, DC: Center for Strategic and International Studies; 2011. p. 21-9.

Yang ZP, Fan DM. How to solve the crisis behind Bribegate for Chinese doctors. Lancet. 2012;379(9812):e13-5.

Yang L, Cui Y, Guo S, Brant P, Li B, Hipgrave D. Evaluation, in three provinces, of the introduction and impact of China's National Essential Medicines Scheme. Bull World Health Organ. 2013a;91:184-94.

Yang G, Wang Y, Zeng Y, Gao GF, Liang X, Zhou M, et al. Rapid health transition in China, 1990-2010: findings from the Global Burden of Disease Study 2010. Lancet. 2013b;381(9882):1987-2015. Epub 12 June 2013.

Yip WC-M, Hsiao WC, Chen W, Hu S, Ma J, Maynard A. Early appraisal of China's huge and complex healthcare reforms. Lancet. 2012;379(9818):833-42.

Youlong G, Wilkes A, Bloom G. Health human resource development in rural China. Health Policy Plan. 1997;12(4):320-8. Epub 3 Nov 1997.

Yu X, Li C, Shi Y, Yu M. Pharmaceutical supply chain in China: current issues and implications for health system reform. Health Policy. 2010;97(1):8-15. Epub 24 Mar 2010.
Zhan SK, Tang SL, Guo YD, Bloom G. Drug prescribing in rural health facilities in China: implications for service quality and cost. Trop Doct. 1998;28(1):42-8. Epub 3 Mar 1998.

Zhang W, Navarro V. Why hasn't China's high-profile health reform (2003-2012) delivered? An analysis of its neoliberal roots. Crit Soc Policy. 2014;34:175-98.

Zhang J, Zhang X, Qiu L, Zhang R, Hipgrave D, Wang Y, et al. Maternal deaths among rural-urban migrants in China: a case-control study. BMC Public Health. 2014;14:512.

Zheng M, Fu Q, Wang X. Comparative study on structural changes in income disparities in urban households in Chongqing Municipality, Shanghai Municipality and Sichuan Province. J Reform Strategy. 2008;5:98-101.

Zhou LA. Reforming China's local government governance. In: Incentives and governance: China's local governments. Singapore: Cengage Learning Asia Pte. Ltd.; 2010a.

Zhou LA. Incentives and governance: China's local governments. Singapore: Cengage Learning Asia Pte. Ltd.; 2010 b.

Zhou L, Conner KR, Caine ED, Xiao S, Xu L, Gong Y, et al. Epidemiology of alcohol use in rural men in two provinces of China. J Stud Alcohol Drugs. 2011;72 (2):333-40. Epub 11 Mar 2011. 